\title{
A Hierarchy of Proof Rules for Checking Differential Invariance of Algebraic Sets
}

\author{
Khalil Ghorbal $^{1} \quad$ Andrew Sogokon ${ }^{2}$ \\ André Platzer ${ }^{1}$
}

November 2014

CMU-CS-14-140

\author{
School of Computer Science \\ Carnegie Mellon University \\ Pittsburgh, PA, 15213
}

\begin{abstract}
To appear [13] in the Proceedings of the
16th International Conference on Verification, Model Checking, and Abstract Interpretation
\end{abstract}

(VMCAI 2015),

12-14 January 2015, Mumbai, India.

${ }^{1}$ Carnegie Mellon University, Computer Science Department, Pittsburgh, PA, USA

\{kghorbal|aplatzer\}ecs.cmu.edu

${ }^{2}$ University of Edinburgh, LFCS, School of Informatics, Edinburgh, Scotland, UK

a.sogokonesms.ed.ac.uk

This material is based upon work supported by the National Science Foundation (NSF) under NSF CAREER Award CNS-1054246, NSF EXPEDITION CNS-0926181, NSF CNS-0931985, by DARPA under agreement number FA8750-12-2-029, as well as the Engineering and Physical Sciences Research Council (UK) under grant EP/I010335/1. The views and conclusions contained in this document are those of the authors and should not be interpreted as representing the official policies, either expressed or implied, of any sponsoring institution or government. 


\section{Report Documentation Page}

Form Approved

OMB No. 0704-0188

Public reporting burden for the collection of information is estimated to average 1 hour per response, including the time for reviewing instructions, searching existing data sources, gathering and maintaining the data needed, and completing and reviewing the collection of information. Send comments regarding this burden estimate or any other aspect of this collection of information,

including suggestions for reducing this burden, to Washington Headquarters Services, Directorate for Information Operations and Reports, 1215 Jefferson Davis Highway, Suite 1204, Arlington

VA 22202-4302. Respondents should be aware that notwithstanding any other provision of law, no person shall be subject to a penalty for failing to comply with a collection of information if it

does not display a currently valid OMB control number.

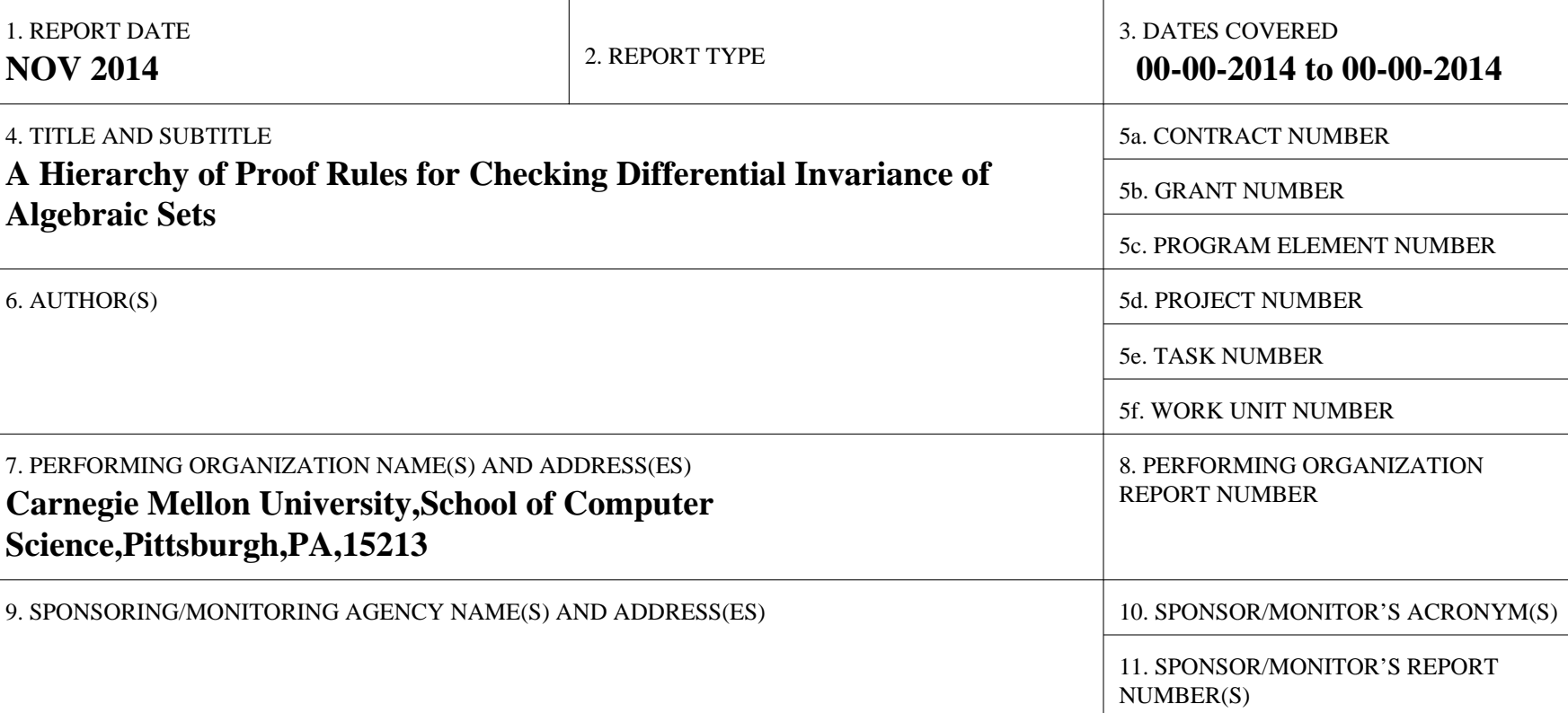

12. DISTRIBUTION/AVAILABILITY STATEMENT

Approved for public release; distribution unlimited

13. SUPPLEMENTARY NOTES

14. ABSTRACT

This paper presents a theoretical and experimental comparison of sound proof rules for proving invariance of algebraic sets, that is, sets satisfying polynomial equalities, under the flow of polynomial ordinary differential equations. Problems of this nature arise in formal verification of continuous and hybrid dynamical systems, where there is an increasing need for methods to expedite formal proofs. We study the trade-off between proof rule generality and practical performance and evaluate our theoretical observations on a set of heterogeneous benchmarks. The relationship between increased deductive power and running time performance of the proof rules is far from obvious; we discuss and illustrate certain classes of problems where this relationship is interesting.

15. SUBJECT TERMS

16. SECURITY CLASSIFICATION OF:

\begin{tabular}{c|c|c}
$\begin{array}{c}\text { a. REPORT } \\
\text { unclassified }\end{array}$ & $\begin{array}{c}\text { b. ABSTRACT } \\
\text { unclassified }\end{array}$ & $\begin{array}{c}\text { c. THIS PAGE } \\
\text { unclassified }\end{array}$
\end{tabular}

\begin{tabular}{c|c|l}
$\begin{array}{c}\text { 17. LIMITATION OF } \\
\text { ABSTRACT }\end{array}$ & $\begin{array}{c}\text { 18. NUMBER } \\
\text { OF PAGES }\end{array}$ & 19a. NAME OF \\
Same as & $\mathbf{3 1}$ & \\
Report (SARSIBLE PERSON & & \\
\hline
\end{tabular}


Keywords: algebraic invariant, deductive power, hierarchy, proof rules, differential equation, abstraction, continuous dynamics, formal verification, hybrid system 


\begin{abstract}
This paper presents a theoretical and experimental comparison of sound proof rules for proving invariance of algebraic sets, that is, sets satisfying polynomial equalities, under the flow of polynomial ordinary differential equations. Problems of this nature arise in formal verification of continuous and hybrid dynamical systems, where there is an increasing need for methods to expedite formal proofs. We study the trade-off between proof rule generality and practical performance and evaluate our theoretical observations on a set of heterogeneous benchmarks. The relationship between increased deductive power and running time performance of the proof rules is far from obvious; we discuss and illustrate certain classes of problems where this relationship is interesting.
\end{abstract}





\section{Introduction}

In safety verification of dynamical systems, either purely continuous or hybrid [24, 32], one is typically concerned with ensuring that by initializing a system in some set of states $X_{0} \subseteq X$ (where $X$ is the state space), the system will never evolve into an unsafe state (belonging to some $\left.X_{u} \subseteq X\right)$. When the system is given by ordinary differential equations $\dot{\boldsymbol{x}}=\boldsymbol{p}(\boldsymbol{x})$, one may attempt to solve this problem by showing that the solution to the initial value problem, for any initial value $\boldsymbol{x}_{0} \in X_{0}$, cannot enter the unsafe region; that is, $\boldsymbol{x}\left(\boldsymbol{x}_{0}, t\right) \notin X_{u}$ for all $t \geq 0$, where $\boldsymbol{x}\left(\boldsymbol{x}_{0}, t\right)$ is the state of the system at time $t$ w.r.t. the initial value $\boldsymbol{x}_{0}$. This safety verification problem is equivalent to showing that the intersection of the reachable set $\left\{\boldsymbol{x}\left(\boldsymbol{x}_{0}, t\right) \in X \mid t \geq 0\right\}$ with the set of unsafe states is empty. However, solutions to ordinary differential equations will rarely be available in closed form; and even when they are, will often be much more complicated than the differential equations themselves. Instead, it is possible to work with the differential equations directly [29, 23, 25, 32].

A fundamental notion in safety verification is that of an invariant set. In fact, exact reachable sets of any given state $\boldsymbol{x}_{0}$ of the system are the smallest invariant sets one can hope to find that include $\boldsymbol{x}_{0}$. However, obtaining and working with exact descriptions of reachable sets is not always practical or even possible. This does not mean that system safety cannot be established by other means - if one finds a larger invariant set, $I \subseteq X$, with a simpler (perhaps algebraic) description which contains the reachable set and does not itself intersect the set of unsafe states (i.e. $I \cap X_{u}=$ $\emptyset)$, then one can soundly conclude that the system is safe. In this paper, we focus on checking whether a given set is an invariant region from which no system trajectory can escape.

Hybrid systems verification completely reduces to questions about invariant regions [22, 24]. We focus on the important case where the invariant regions are algebraic sets, i.e. can be defined by polynomial equations. Many sound proof rules already exist for deciding invariance properties of algebraic sets. However, in order to identify a good trade-off, it is crucial to study the relationship between the deductive power and the practical running time performance of these proof rules.

Contributions. (I) We theoretically compare the deductive power of 7 different proof rules for checking invariance properties of algebraic sets under the flow of polynomial ordinary differential equations. Further, we assess the practical utility of each of these rules in order to identify a good trade-off between generality and running time performance. (II) We investigate the effect of square-free reduction on both the deductive power and the computational complexity of the proof rules. (III) We assess the practical proof rule performance on a heterogeneous set of 75 benchmarks. We demonstrate the counter-intuitive fact that square-free reduction does not necessarily improve the computational efficiency of certain proof rules and explore interesting connections between the deductive power and the practical running time performance that we observe for the proof rules.

Content. In Section 2, we recall some basic definitions and concepts that will be used throughout the paper. We then introduce (in Section 3) two proof rules that serve as extensions of Lie's criterion for equational invariants. In Section 4, we compare the deductive power of the proof rules. The benefits and drawbacks of performing square-free reduction as a pre-processing step are investigated in Section 5. In Section 6, we present the set of benchmarks and our experimental results. We finally discuss other related work in Section 7 before concluding. 


\section{Preliminaries}

We consider autonomous ${ }^{1}$ polynomial vector fields (see Def. 1 below).

Let $\boldsymbol{x}=\left(x_{1}, \ldots, x_{n}\right) \in \mathbb{R}^{n}$, and $\boldsymbol{x}(t)=\left(x_{1}(t), \ldots, x_{n}(t)\right)$, where $x_{i}: \mathbb{R} \rightarrow \mathbb{R}, t \mapsto x_{i}(t)$. The ring of polynomials over the reals will be denoted by $\mathbb{R}\left[x_{1}, \ldots, x_{n}\right]$.

Definition 1 (Polynomial Vector Field). Let $p_{i}, 1 \leq i \leq n$, be multivariate polynomials of the polynomial ring $\mathbb{R}[\boldsymbol{x}]$. A polynomial vector field, $\boldsymbol{p}$, is an explicit system of ordinary differential equations with polynomial right-hand side:

$$
\frac{d x_{i}}{d t}=\dot{x}_{i}=p_{i}(\boldsymbol{x}), \quad 1 \leq i \leq n
$$

Since polynomial functions are smooth $\left(C^{\infty}\right.$, i.e. they have derivatives up to any order), they are locally Lipschitz-continuous. By the Cauchy-Lipschitz theorem (a.k.a. Picard-Lindelöf) [16], there exists a unique maximal solution to the initial value problem $\left(\dot{\boldsymbol{x}}=\boldsymbol{p}, \boldsymbol{x}(0)=\boldsymbol{x}_{0}\right)$ defined for $t$ in some nonempty open interval.

For $h \in \mathbb{R}\left[x_{1} \ldots, x_{n}\right]$, if $h(\boldsymbol{x}(t))=0$ for all $t \geq 0$, we say that the equation $h=0$ is a (positive) invariant under the flow of $\boldsymbol{p}$. In differential dynamic logic [22], invariance of $h=0$ is semantically equivalent to the validity of the following formula:

$$
(h=0) \rightarrow[\dot{\boldsymbol{x}}=\boldsymbol{p}](h=0)
$$

Geometrically, the equation $h=0$ represents the set of real roots of $h$. Such a set is known as real algebraic set or a real variety and will be henceforth denoted by $V_{\mathbb{R}}(h)$. Algebraic sets are intimately related to sets of polynomials with special algebraic properties called ideals. Ideals are closed under addition and external multiplication; that is, if $I$ is an ideal, then for all $h_{1}, h_{2} \in I$, the sum $h_{1}+h_{2} \in I$; and if $h \in I$, then, $q h \in I$, for all $q \in \mathbb{R}\left[x_{1} \ldots, x_{n}\right]$. To say that the real variety $V_{\mathbb{R}}(h)$ of the ideal generated by $h$ is invariant under the flow of the vector field $\boldsymbol{p}$ is equivalent to the statement that the equation $h=0$ is invariant.

We will use $\nabla h$ to denote the gradient of $h: \mathbb{R}^{n} \rightarrow \mathbb{R}$, that is the vector of its partial derivatives $\left(\frac{\partial h}{\partial x_{1}}, \ldots, \frac{\partial h}{\partial x_{n}}\right)$. The Lie derivative of $h$ along the vector field $\boldsymbol{p}$ gives the rate of change of $h$ along the flow of $\dot{\boldsymbol{x}}=\boldsymbol{p}(\boldsymbol{x})$ and is formally defined as the scalar product of $\nabla h$ and $\boldsymbol{p}$.

$$
\mathfrak{L}_{\boldsymbol{p}}(h) \stackrel{\text { def }}{=} \nabla h \cdot \boldsymbol{p}
$$

Higher-order Lie derivatives are defined recursively as $\mathfrak{L}_{\boldsymbol{p}}^{(k+1)}(h)=\mathfrak{L}_{\boldsymbol{p}}\left(\mathfrak{L}_{\boldsymbol{p}}^{(k)}(h)\right)$, with $\mathfrak{L}_{\boldsymbol{p}}^{(0)}(h)=h$.

We now recall five important proof rules for checking invariance of polynomial equalities, or equivalently the validity of Eq. (2). In Fig. 1, DI = shows the differential invariant [23] proof rule restricted to handling equalities. The condition imposed by the premise of $\mathrm{DI}_{=}$is sufficient, but not necessary; it characterizes polynomial invariant functions. The premise of the Polynomialscale consecution proof rule [29], P-c in Fig. 1, requires $\mathfrak{L}_{p}(h)$ to be in the ideal generated by $h$.

\footnotetext{
${ }^{1}$ That is, the rate of change of the system over time depends only on the system's state, not on time. Nonautonomous systems with polynomial time-dependence can be made autonomous by adding an extra clock variable that reflects the progress of time.
} 


$$
\begin{gathered}
\left(\mathrm{DI}_{=}\right) \frac{\mathfrak{L}_{\boldsymbol{p}}(h)=0}{(h=0) \rightarrow[\dot{\boldsymbol{x}}=\boldsymbol{p}](h=0)} \quad(\mathrm{C}-\mathrm{c}) \frac{\exists \lambda \in \mathbb{R}, \mathfrak{L}_{\boldsymbol{p}}(h)=\lambda h}{(h=0) \rightarrow[\dot{\boldsymbol{x}}=\boldsymbol{p}](h=0)} \\
(\mathrm{Lie}) \frac{h=0 \rightarrow\left(\mathfrak{L}_{\boldsymbol{p}}(h)=0 \wedge \nabla h \neq \mathbf{0}\right)}{(h=0) \rightarrow[\dot{\boldsymbol{x}}=\boldsymbol{p}](h=0)} \\
(\mathrm{P}-\mathrm{c}) \frac{\mathfrak{L}_{\boldsymbol{p}}(h) \in\langle h\rangle}{(h=0) \rightarrow[\dot{\boldsymbol{x}}=\boldsymbol{p}](h=0)} \\
(\mathrm{DRI}) \frac{h=0 \rightarrow \bigwedge_{i=0}^{N-1} \mathfrak{L}_{\boldsymbol{p}}^{(i)}(h)=0}{(h=0) \rightarrow[\dot{\boldsymbol{x}}=\boldsymbol{p}](h=0)}
\end{gathered}
$$

Figure 1: Proof rules for checking the invariance of $h=0$ w.r.t. $p$ : $\mathrm{DI}_{=}[25$, Theorem 3], C-c and P-c [29, Lemma 2], Lie [21, Theorem 2.8], DRI [11, Theorem 2]

The condition is also only sufficient (but is particularly suitable for generating invariant varieties [18]). We also consider the constant-scale consecution proof rule [29, 32], denoted by C-c. The premise of proof rule $\mathrm{C}$-c requires that $\mathfrak{L}_{p}(h)=\lambda h$, where $\lambda$ is a scalar, not a polynomial as in P-c. It is therefore a simple special case of P-c. When $\lambda=0$, one obtains the premise of the proof rule $\mathrm{DI}_{=}$. It is worth noting that $\mathrm{P}-\mathrm{c}$, including its special case $\mathrm{C}-\mathrm{c}$, was mentioned as early as 1878 [6] and used extensively in the study of integrability of dynamical systems, where they are known as second integrals [14, Chapter 2]. It serves as a natural extension to invariant functions, also known as first integrals, which are covered by the proof rule $\mathrm{DI}_{=}$. The proof rule Lie gives Lie's criterion $[15,21]$ for invariance of $h=0$; this proof rule will be discussed in more depth and extended to handle tricky cases in Section 3. The last rule, DRI in Fig. 1, was recently introduced and characterizes (i.e. gives necessary and sufficient conditions for) invariant varieties under the flow of polynomial vector fields [11]. The number $N$ in DRI is the maximum length of the ascending chain of polynomial ideals $\langle h\rangle \subset\left\langle h, \mathfrak{L}_{\boldsymbol{p}}(h)\right\rangle \subset\left\langle h, \mathfrak{L}_{\boldsymbol{p}}(h), \mathfrak{L}_{\boldsymbol{p}}^{(2)}(h)\right\rangle \subset \cdots$, which is finite and computable [11].

\section{Lie's Criterion}

One immediate (and somewhat embarrassing) deficiency of the proof rule Lie (Fig. 1) is its inability to prove invariance properties for isolated points (e.g. system equilibria) for the simple reason that a description of such a point $\boldsymbol{a}=\left(a_{1}, \ldots, a_{n}\right) \in \mathbb{R}^{n}$ is (when $n>1$ ) given by the sum-of-squares equation $h(\boldsymbol{x})=\left(x_{1}-a_{1}\right)^{2}+\cdots+\left(x_{n}-a_{n}\right)^{2}=0$. This sum-of-squares polynomial $h$ is positive-definite, i.e. $h(\boldsymbol{a})=0$ and $h(\boldsymbol{x})>0$ for all $\boldsymbol{x} \in \mathbb{R}^{n} \backslash\{\boldsymbol{a}\}$. Positive definite functions have vanishing gradient at their minima, in this case $\boldsymbol{a}$, and thus the formula $h=0 \rightarrow \nabla h=\mathbf{0}$ holds. This violates the regularity condition in the premise of the proof rule Lie, namely:

$$
h=0 \longrightarrow \nabla h \neq \mathbf{0}
$$

In fact, $h=0 \rightarrow \mathfrak{L}_{\boldsymbol{p}}(h)=0$ is a necessary condition when $h=0$ is an invariant equation. Note that simply removing Eq. (4) from the premise of the proof rule Lie is unsound (see e.g. [25]); 
that is, the condition $h=0 \rightarrow \mathfrak{L}_{\boldsymbol{p}}(h)=0$ alone is insufficient to prove the invariance property for $h=0$. Unsoundness in the above naïve attempt at a generalization is a consequence of singularities that may be present in the variety $V_{\mathbb{R}}(h)$. Singularities of $V_{\mathbb{R}}(h)$ are points $\boldsymbol{x} \in V_{\mathbb{R}}(h)$ where the gradient of $h$ vanishes, i.e. $\nabla h(\boldsymbol{x})=\mathbf{0}$.

Definition 2 (Singular Locus). Let $h \in \mathbb{R}\left[x_{1}, \ldots, x_{n}\right]$, the singular locus of $h=0$, henceforth denoted $\mathrm{SL}(h)$, is the set of singular points, that is, points $\boldsymbol{x}$ satisfying

$$
h=0 \wedge \frac{\partial h}{\partial x_{1}}=0 \wedge \cdots \wedge \frac{\partial h}{\partial x_{n}}=0 .
$$

Points that are not singular are called regular. At singular points, the Lie derivative of $h$ along any vector field is $\mathbf{0} \cdot \boldsymbol{p}=0$. To avoid these degenerate cases, the regularity condition (Eq. (4)) rules out singularities altogether. In the next section we present two extensions of Lie's criterion that, in a similar vein to [30], partially overcome the strong regularity condition by treating the points on the singular locus separately.

\subsection{Handling Singularities}

Equilibria are points in the state space where the vector field vanishes $(\boldsymbol{p}=0)$ so that there is no motion. However, as seen above, Lie's criterion cannot generally be applied to prove invariance properties of isolated equilibria because their description involves singularities. One simple way to resolve this issue is to drop the non-vanishing gradient condition and replace it with the proviso that there be no flow (that is $\boldsymbol{p}=\mathbf{0}$ ) in the variables of the invariant candidate on the singular locus; this will allow singularities in the invariant candidate and will provide a sound proof method in which there is no need to check for non-vanishing gradient. Below we present two extensions to the proof rule Lie and justify their soundness after recalling some basic geometric notions.

Definition 3 ( $\mathrm{Lie}^{\circ}$ : Lie + Equilibria).

$$
\left(\operatorname{Lie}^{\circ}\right) \frac{h=0 \rightarrow\left(\mathfrak{L}_{\boldsymbol{p}}(h)=0 \wedge\left(\mathrm{SL}(h) \rightarrow \bigwedge_{x_{i} \in \operatorname{vars}(h)} p_{i}=0\right)\right)}{(h=0) \rightarrow[\dot{\boldsymbol{x}}=\boldsymbol{p}](h=0)},
$$

where vars $(h)$ denotes the set of state variables $x_{i}$ occurring in the polynomial $h$.

The $\mathrm{Lie}^{\circ}$ proof rule can be generalized further at the expense of adding an extra variable by replacing the "no flow" condition $\left(p_{i}=0\right)$ for points on the singular locus with $\forall \lambda . h(\boldsymbol{x}+\lambda \boldsymbol{p}(\boldsymbol{x}))=$ 0 , where $\lambda$ is a fresh symbol.

Definition 4 (Lie*: Lie + Vanishing Sub-tangent).

$$
\left(\mathrm{Lie}^{*}\right) \frac{h=0 \rightarrow\left(\mathfrak{L}_{\boldsymbol{p}}(h)=0 \wedge(\mathrm{SL}(h) \rightarrow h(\boldsymbol{x}+\lambda \boldsymbol{p})=0)\right)}{(h=0) \rightarrow[\dot{\boldsymbol{x}}=\boldsymbol{p}](h=0)} .
$$


To prove soundness of $\mathrm{Lie}^{\circ}$ and $\mathrm{Lie}^{*}$, we use a result about positive invariance of closed sets under locally Lipschitz-continuous vector fields, known as the Nagumo theorem [20, 33, Chapter 10, XV-XVI, pp. 117-119], which gives a powerful (but generally intractable) geometric characterization of positively invariant closed sets. The notion of positive invariance of the equation $h=0$ from Section 2 generalizes to an arbitrary set.

Definition 5 (Invariant Sets). A set $S$ is positively (negatively) invariant under the flow of $\dot{\boldsymbol{x}}=\boldsymbol{p}$ if for all $\boldsymbol{x}_{0} \in S$ we have $\boldsymbol{x}\left(\boldsymbol{x}_{0}, t\right) \in S$ for all $t \geq 0(t \leq 0)$, where $\boldsymbol{x}\left(\boldsymbol{x}_{0}, t\right)$ is the solution of the initial value problem $\left(\dot{\boldsymbol{x}}=\boldsymbol{p}, \boldsymbol{x}(0)=\boldsymbol{x}_{0}\right)$. A set $S$ is bi-invariant if it is both positively and negatively invariant.

Nagumo's theorem needs the geometric notion of sub-tangential vectors to a set.

Definition 6 (Sub-tangent vector). A vector $\boldsymbol{v} \in \mathbb{R}^{n}$ is sub-tangential to a set $S$ at $\boldsymbol{x} \in S$ if

$$
\liminf _{\lambda \rightarrow 0^{+}} \frac{\operatorname{dist}(S, \boldsymbol{x}+\lambda \boldsymbol{v})}{\lambda}=0,
$$

where dist denotes the Euclidean set distance, i.e. $\operatorname{dist}(S, \boldsymbol{x}) \equiv \inf _{\boldsymbol{y} \in S}\|\boldsymbol{x}-\boldsymbol{y}\|$.

Theorem 1 (Nagumo Theorem). Given a continuous system $\dot{\boldsymbol{x}}=\boldsymbol{p}(\boldsymbol{x})$ and assuming that solutions exist and are unique inside some open set $O \subseteq \mathbb{R}^{n}$, let $S \subset O$ be a closed set. Then, $S$ is positively invariant under the flow of the system if and only if $\boldsymbol{p}(\boldsymbol{x})$ is sub-tangential to $S$ for all $\boldsymbol{x} \in \partial S$, where $\partial S$ is the boundary of $S$.

Let us observe that given $\boldsymbol{x} \in \partial S$, if $\boldsymbol{x}+\lambda \boldsymbol{p}(\boldsymbol{x}) \in S$ for all $\lambda \in \mathbb{R}$, then $\operatorname{dist}(S, \boldsymbol{x}+\lambda \boldsymbol{p}(x))=0$ and $\boldsymbol{p}(\boldsymbol{x})$ is sub-tangential to $S$ at $\boldsymbol{x}$. This observation is important for algebraic sets, for which $\partial S=S$, and the condition $\boldsymbol{x}+\lambda \boldsymbol{p}(\boldsymbol{x}) \in S$ translates to $h(\boldsymbol{x}+\lambda \boldsymbol{p}(\boldsymbol{x}))=0$. This is the main idea behind the soundness of the proof rule Lie*.

Proposition 1. The proof rule Lie* is sound.

Proof. A point on the variety is either regular or singular. For regular points (these form an open subset of the variety), since $\mathfrak{L}_{\boldsymbol{p}}(h)(\boldsymbol{x})=0$, the vector $\boldsymbol{p}(\boldsymbol{x})$ is sub-tangent to the variety at $\boldsymbol{x}$ (in fact, it is even tangent, so the condition we check is exactly that which is used in Lie). At singular points $\boldsymbol{x} \in V_{\mathbb{R}}(h)$ if $h(\boldsymbol{x}+\lambda \boldsymbol{p}(\boldsymbol{x}))=0$ holds for all $\lambda$ then $\operatorname{dist}\left(V_{\mathbb{R}}(h), \boldsymbol{x}+\lambda \boldsymbol{p}(\boldsymbol{x})\right)=0$ for all $\lambda$, from which it follows that $\liminf _{\lambda \rightarrow 0^{+}} \frac{\operatorname{dist}\left(V_{\mathbb{R}}(h), \boldsymbol{x}+\lambda \boldsymbol{p}(\boldsymbol{x})\right)}{\lambda}=0$ and thus $\boldsymbol{p}(\boldsymbol{x})$ is sub-tangential to $V_{\mathbb{R}}(h)$ at $\boldsymbol{x}$. Assuming solutions exist and are unique, the variety $V_{\mathbb{R}}(h)$ is positively invariant under the vector field $\boldsymbol{p}$ by Nagumo's theorem.

The case $\boldsymbol{p}(\boldsymbol{x})=0$ for all $\boldsymbol{x}$ in the singular locus is a special case of the proof rule Lie* Therefore, the soundness of $\mathrm{Lie}^{\circ}$ is an immediate corollary of Prop. 1.

Corollary 1. The proof rule $\mathrm{Lie}^{\circ}$ is sound.

Remark 1. It is worth remarking that proof rules presented in this section, as well as Lie and $\mathrm{DI}_{=}$, also work for non-polynomial vector fields and invariant candidates which themselves are not polynomial but sufficiently smooth. However, in such cases the resulting arithmetic may no longer be decidable [28]. 


\section{Proof Rules: Hierarchy and Complexity}

In this section, we compare the deductive power of the existing (Fig. 1) and the newly-introduced proof rules $\left(\mathrm{Lie}^{\circ}\right.$ and $\mathrm{Lie}^{*}$ in Section 3 ) for checking the invariance of algebraic sets. This study should be complemented by another comparison that considers the interaction between the different proof rules in the context of a formal proof system in a similar vein to [26]. We leave this for future work.

Given two proof rules (let us call them $R_{1}$ and $R_{2}$ ) featuring the same conclusion

$$
(h=0) \longrightarrow[\dot{\boldsymbol{x}}=\boldsymbol{p}](h=0),
$$

we will say that $R_{2}$ generalizes $R_{1}$ and write $R_{2} \succcurlyeq R_{1}$ (or $R_{1} \preccurlyeq R_{2}$ ), if the premise of $R_{1}$ implies the premise of $R_{2}$. That is, if $R_{1}$ proves that $h=0$ is an invariant, then so does $R_{2}$. If $R_{1} \preccurlyeq R_{2}$ and $R_{1} \succcurlyeq R_{2}$, we say that $R_{1}$ and $R_{2}$ are equivalent, and denote this by $R_{1} \sim R_{2}$. Likewise, $R_{1} \npreceq R_{2}$ (or $R_{2} \nsucc R_{1}$ ) denotes that $R_{1}$ is not generalized by $R_{2}$. We also write $R_{1} \prec R_{2}$ when $R_{1} \preccurlyeq R_{2}$ and $\mathrm{R}_{1} \nsucc \mathrm{R}_{2}$. That is, the rule $\mathrm{R}_{2}$ increases the deductive power of $\mathrm{R}_{1}$.

It is easy to see that the order $\preccurlyeq$ is a partial order (with $\sim$ acting as equality): it is reflexive, $\mathrm{R} \preccurlyeq \mathrm{R}$ (the premise of $\mathrm{R}$ implies itself); it is anti-symmetric (by definition), and transitive: if $R_{1} \preccurlyeq R_{2}$ and $R_{2} \preccurlyeq R_{3}$, then the premise of $R_{1}$ implies the premise of $R_{3}$ by transitivity of the implication, so $R_{1} \preccurlyeq R_{3}$. Finally, If $R_{1} \npreceq R_{2}$ and $R_{1} \nsucc R_{2}$, we will write $R_{1} \prec \succ R_{2}$ and say that the proof rules $R_{1}$ and $R_{2}$ are incomparable. This means that for both $R_{1}$ and $R_{2}$ there are problems that one rule can prove and the other cannot. In the sequel, we use the partial order $\preccurlyeq$ to illustrate the lattice structure of the proof rules under consideration. In Section 4.2 we discuss the computational complexity of the conditions appearing in their premises.

\subsection{Hierarchy}

We use the partial order $(\preccurlyeq)$ to compare the deductive power of all considered proof rules

$$
\left\{\mathrm{DI}_{=}, \mathrm{C}-\mathrm{c}, \mathrm{P}-\mathrm{c}, \mathrm{Lie}, \mathrm{Lie}^{\circ}, \mathrm{Lie}^{*}, \mathrm{DRI}\right\} \text {. }
$$

For convenience, the propositions of this section are summarized in the comparison matrix (Fig. 3). For instance, Prop. 6 proves that $\mathrm{DI}_{=} \prec \succ$ Lie. Cells without numbers are proved by transitivity of the partial order. For instance, $\mathrm{DI}_{=} \prec \mathrm{DRI}$ can be proved using $\mathrm{DI}_{=} \prec \mathrm{C}$-c (Prop. 2) and C-c $\prec$ P-c (Prop. 3) and P-c $\prec$ DRI (Prop. 5). The Hasse diagram (Fig. 2) gives the lattice structure where arrows represent strictly increasing deductive power; every missing edge in the graph represents $\prec \succ$, as shown in the comparison matrix.

We begin by comparing Darboux-based proof rules, i.e. $\left\{\mathrm{DI}_{=}, \mathrm{C}-\mathrm{c}, \mathrm{P}-\mathrm{c}\right\}$ and then proceed to the Lie-based proof rule family, i.e. $\left\{\mathrm{Lie}, \mathrm{Lie}^{\circ}, \mathrm{Lie}^{*}\right\}$. Next, we demonstrate the deductive superiority of the necessary and sufficient conditions in the premise of the proof rule DRI. Finally, we establish that Darboux-based proof rules and Lie-based proof rules form two distinct proof rule families; that is, any proof rule from one family is deductively incomparable to any proof rule from the other family.

Proposition 2. $\mathrm{DI}_{=} \prec \mathrm{C}-\mathrm{c}$. 


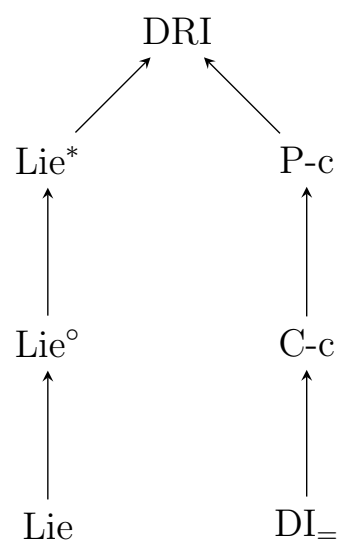

Figure 2: Hasse diagram. An arrow $\mathrm{R}_{1} \rightarrow \mathrm{R}_{2}$ means $\mathrm{R}_{1} \prec$ $\mathrm{R}_{2}$, all other non depicted links mean $(\prec \succ)$.

\begin{tabular}{|c|c|c|c|c|c|c|c|}
\hline & $\mathrm{DI}_{=}$ & C-c & $\mathrm{P}-\mathrm{c}$ & Lie & $\mathrm{Lie}^{\circ}$ & $\mathrm{Lie}^{*}$ & DRI \\
\hline $\mathrm{DI}_{=}$ & $\sim$ & $\begin{array}{l}\prec \\
2\end{array}$ & $\prec$ & $\begin{array}{c}\prec \succ \\
6\end{array}$ & $\begin{array}{c}\prec \succ \\
8\end{array}$ & $\begin{array}{c}\prec \succ \\
7\end{array}$ & $\prec$ \\
\hline C-c & $\succ_{2}$ & $\sim$ & $\begin{array}{l}\prec \\
3\end{array}$ & $\begin{array}{c}\prec \succ \\
9\end{array}$ & $\begin{array}{c}\prec \succ \\
10\end{array}$ & $\begin{array}{c}\prec \succ \\
10\end{array}$ & $\prec$ \\
\hline $\mathrm{P}-\mathrm{c}$ & $\succ$ & $\succ$ & $\sim$ & $\begin{array}{c}\prec \succ \\
9\end{array}$ & $\begin{array}{c}\prec \succ \\
10\end{array}$ & $\begin{array}{l}\prec \succ \\
10\end{array}$ & $\begin{array}{l}\prec \\
5\end{array}$ \\
\hline Lie & $\begin{array}{c}\prec \succ \\
6\end{array}$ & $\begin{array}{c}\prec \succ \\
9\end{array}$ & $\begin{array}{c}\prec \succ \\
9\end{array}$ & $\sim$ & $\begin{array}{l}\prec \\
4\end{array}$ & $\prec$ & $\prec$ \\
\hline $\mathrm{Lie}^{\circ}$ & $\begin{array}{c}\prec \succ \\
8\end{array}$ & $\begin{array}{l}\prec \succ \\
10\end{array}$ & $\begin{array}{l}\prec \succ \\
10\end{array}$ & $\succ_{4}$ & $\sim$ & $\begin{array}{l}\prec \\
4\end{array}$ & $\prec$ \\
\hline $\mathrm{Lie}^{*}$ & $\begin{array}{c}\prec \succ \\
7\end{array}$ & $\begin{array}{c}\prec \succ \\
10\end{array}$ & $\begin{array}{l}\prec \succ \\
10\end{array}$ & $\succ$ & $\succ_{4}$ & $\sim$ & $\begin{array}{l}\prec \\
5\end{array}$ \\
\hline DRI & $\succ$ & $\succ$ & $\succ$ & $\succ$ & $\succ$ & $\succ$ & $\sim$ \\
\hline
\end{tabular}

Figure 3: Comparison matrix of the deductive power of $\left\{\mathrm{DI}=, \mathrm{C}-\mathrm{c}, \mathrm{P}-\mathrm{c}, \mathrm{Lie}, \mathrm{Lie}^{\circ}, \mathrm{Lie}^{*}, \mathrm{DRI}\right\}$. The numbers refer to the propositions.

Proof. The premise of the rule C-c requires the existence of some $\lambda \in \mathbb{R}$, such that $\mathfrak{L}_{p}(h)=\lambda h$. In particular, $\lambda=0$ gives the premise of $\mathrm{DI}_{=}$. Thus, $\mathrm{DI}_{=} \preccurlyeq \mathrm{C}$-c. To see that $\mathrm{DI}_{=} \nsucc \mathrm{C}$-c, consider the one-dimensional vector field $\boldsymbol{p}=(x)$, we have $\mathfrak{L}_{\boldsymbol{p}}(x)=1 x$, and hence $\mathrm{C}$-c $(\lambda=1)$ concludes that $x=0$ is an invariant. However, $\mathrm{DI}_{=}$cannot prove the invariance of $x=0$ because $x$ is not a conserved quantity in the system.

Proposition 3. C-c $\prec \mathrm{P}-\mathrm{c}$.

Proof. The premise of the rule P-c requires the existence of some $\alpha \in \mathbb{R}[\boldsymbol{x}]$, such that $\mathfrak{L}_{\boldsymbol{p}}(h)=\alpha h$ (equivalently, $\mathfrak{L}_{\boldsymbol{p}}(h) \in\langle h\rangle$ ). In particular, the constant polynomial gives the premise of C-c. Thus, $\mathrm{C}$-c $\preccurlyeq \mathrm{P}$-c. To prove that $\mathrm{C}$-c $\nsucceq \mathrm{P}$-c, consider he two-dimensional vector field $\boldsymbol{p}=(x y, x)$, we have $\mathfrak{L}_{p}(x)=x y$ (or equivalently $\mathfrak{L}_{p}(x) \in\langle x\rangle \subset \mathbb{R}[x, y]$ ) and hence conclude, using P-c, that $x=0$ is an invariant. However, C-c fails to prove this invariant as the required cofactor is not a scalar.

Proposition 4. Lie $\prec \operatorname{Lie}^{\circ}$ and $\mathrm{Lie}^{\circ} \prec \mathrm{Lie}^{*}$.

Proof. We already established that Lie $\preccurlyeq \mathrm{Lie}^{\circ}$ (Prop. 1) and $\mathrm{Lie}^{\circ} \preccurlyeq \mathrm{Lie}^{*}$ (Prop. 1); we give two counterexamples to establish the strict inclusion. (I) Lie $\npreceq \mathrm{Lie}^{\circ}$. Whenever the variety has a singularity, the proof rule Lie will fail. $\mathrm{Lie}^{\circ}$ is tailored to prove invariance of equilibrium points in addition to regular points of the variety. For instance, for $\boldsymbol{p}=\left(\left(-1+x_{1}\right) x_{2}, x_{2}\left(1+x_{2}\right)\right)$, Lie fails to prove that $h=\left(-1+x_{1}\right)^{2}+\left(1+x_{2}\right)^{2}=0$ is invariant as the gradient $\nabla h$ vanishes at $(1,-1)$ and $h((1,-1))=0$. However, at $(1,-1)$ we also have $p_{1}=p_{2}=0$, and hence the premise of $\mathrm{Lie}^{\circ}$ is satisfied, and $h=0$ is proved to be an invariant under the flow of $\boldsymbol{p}$. (II) $\mathrm{Lie}^{\circ} \npreceq$ Lie* $^{*}$. 

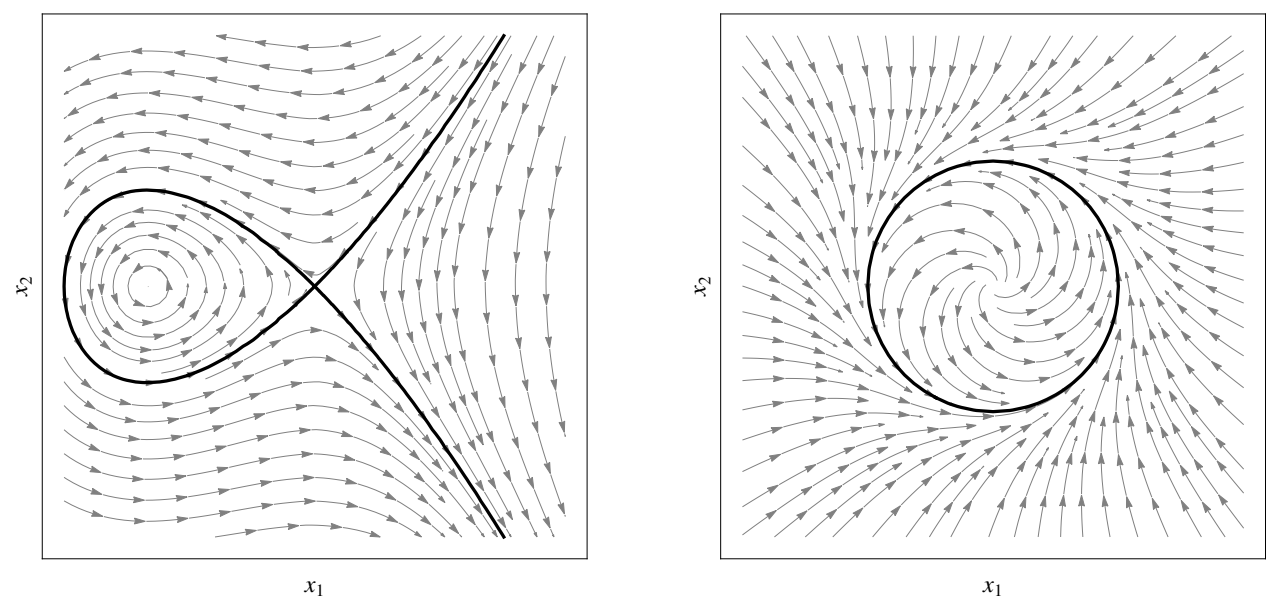

Figure 4: The invariance of the variety $V_{\mathbb{R}}\left(x_{1}^{2}+x_{1}^{3}-x_{2}^{2}\right)$ (left) provable using $\mathrm{DI}_{=}$(but not Lie since $(0,0)$ is a singular point) and a smooth invariant limit cycle $V_{\mathbb{R}}\left(x_{1}^{2}+x_{2}^{2}-1\right)$ (right) provable using Lie (but not $\mathrm{DI}_{=}$since it is not an invariant function).

In addition to equilibria, Lie* goes one step further and handles all singular points, $\boldsymbol{x}$, where the vector $\boldsymbol{x}+\lambda \boldsymbol{p}$ is in the variety $V_{\mathbb{R}}(h)$ for all $\lambda \in \mathbb{R}$ (that is $h(\boldsymbol{x}+\lambda \boldsymbol{p})=0$, for all $\lambda$ ). For instance, consider the polynomial $h=x_{1} x_{2} x_{3}$, its singular locus is given by the three axes $x_{1}=x_{2}=0$, $x_{1}=x_{3}=0$ and $x_{2}=x_{3}=0$. For the vector field $\boldsymbol{p}=\left(x_{1}, x_{2}, x_{3}\right)$, the equilibrium point is at the origin $(0,0,0)$, which obviously does not contain the entire singular locus of $h$. Thus, Lie fails but Lie* succeeds because $h(\boldsymbol{x}+\lambda \boldsymbol{p})=0$ when $\boldsymbol{x}$ is a point of one of the axes.

Proposition 5. P-c $\prec \mathrm{DRI}$ and $\mathrm{Lie}^{*} \prec \mathrm{DRI}$.

Proof. DRI is both necessary and sufficient [11], so we know that $\mathrm{P}-\mathrm{c} \preccurlyeq$ DRI and Lie* $\preccurlyeq$ DRI. To prove the claim it is left to show that (I) P-c $\nsucceq$ DRI. Consider the following two-dimensional vector field: $\boldsymbol{p}=\left(\left(-1+x_{1}\right)\left(1+x_{1}\right),\left(-1+x_{2}\right)\left(1+x_{2}\right)\right)$. The candidate invariant (given by the roots of the Motzkin polynomial) $h=1-3 x_{1}^{2} x_{2}^{2}+x_{1}^{4} x_{2}^{2}+x_{1}^{2} x_{2}^{4}=0$ cannot be proved using P-c, as $\mathfrak{L}_{\boldsymbol{p}}(h) \notin\langle h\rangle$. However, the invariance property may be proved using DRI. For this, we need to consider the second-order Lie derivative of $h$ and we prove that $\mathfrak{L}_{\boldsymbol{p}}^{(2)}(h) \in\left\langle h, \mathfrak{L}_{\boldsymbol{p}}(h)\right\rangle$. Thus, the premise of DRI holds for $N=2$. (II) Lie* $\nsucc$ DRI. Consider the following three-dimensional vector field $\boldsymbol{p}=\left(-x_{2}+x_{1}\left(1-x_{1}^{2}-x_{2}^{2}\right), x_{1}+x_{2}\left(1-x_{1}^{2}-x_{2}^{2}\right), x_{3}\right)$. We want to prove that $h=\left(-1+x_{1}^{2}+x_{2}^{2}\right)^{2}+x_{3}^{2}=0$ is an invariant. In this case, the variety $V_{\mathbb{R}}(h)$ is exactly equal to the singular locus of $h$ which is the two-dimensional unit circle $-1+x_{1}^{2}+x_{2}^{2}=0$. However, at all points of this unit circle, the vector field $\boldsymbol{p}$ is equal to $\left(-x_{2}, x_{1}, 0\right) \neq 0$, which prevents us from using Lie* (because $h\left(\left(x_{1}, x_{2}, 0\right)+\lambda\left(-x_{2}, x_{1}, 0\right)\right) \neq 0$ for some $\left.\lambda \in \mathbb{R}\right)$. The rule DRI proves the invariance of $h=0$ with $N=2$.

To appreciate the difference between $\mathrm{DI}_{=}$and Lie, let us note that while the condition in the premise of $\mathrm{DI}_{=}$may seem strong (i.e. too conservative), singularities in the invariant candidate do not present a problem for $\mathrm{DI}_{=}$, whereas the premise of Lie rules out such candidates altogether (see Fig. 4). Indeed, the proof rule Lie cannot prove that $0=0$ (the whole space is invariant), whereas this is the most trivial case for $\mathrm{DI}_{=}$. 
Proposition $6\left(\mathrm{DI}_{=}\right.$and Lie are incomparable.). $\mathrm{DI}_{=} \prec \succ$ Lie.

Proof. (I) $\mathrm{DI}_{=} \npreceq$ Lie. For the vector field $\boldsymbol{p}=\left(-2 x_{2},-2 x_{1}-3 x_{1}^{2}\right)$, the equation $x_{1}^{2}+x_{1}^{3}-x_{2}^{2}=0$ is provable with $\mathrm{DI}_{=}$but not Lie, see Fig. 4 (left). (II) DI $=\npreceq$ Lie. For the vector field $\boldsymbol{p}=$ $\left(x_{1}-x_{1}^{3}-x_{2}-x_{1} x_{2}^{2}, x_{1}+x_{2}-x_{1}^{2} x_{2}-x_{2}^{3}\right)$, the invariance of the limiting cycle $x_{1}^{2}+x_{2}^{2}-1=0$ is provable with Lie but not $\mathrm{DI}_{=}$, see Fig. 4 (right).

We now prove that Lie-based proof rules $\left\{\mathrm{Lie}, \mathrm{Lie}^{\circ}, \mathrm{Lie}^{*}\right\}$, and Darboux-based proof rules $\left\{\mathrm{DI}_{=}, \mathrm{C}-\mathrm{c}, \mathrm{P}-\mathrm{c}\right\}$ are two distinct families of proof rules; that is, any Lie-based proof is deductively incomparable to any Darboux-based proof rule. The following lemma follows from the transitivity of the partial order.

Lemma 1. If $R_{1} \preccurlyeq R_{2}$ and $R_{3} \prec \succ R_{1}$, then $R_{2} \npreceq R_{3}$.

Proof. Consider three proof rules $R_{1}, R_{2}$ and $R_{3}$. If $R_{2} \preccurlyeq R_{3}$, using $R_{1} \preccurlyeq R_{2}$, one gets by transitivity $R_{1} \preccurlyeq R_{3}$, which contradicts the assumption $R_{3} \prec \succ R_{1}$.

Proposition 7. $\mathrm{DI}_{=} \prec \succ \mathrm{Lie}^{*}$.

Proof. Since Lie $\preccurlyeq \mathrm{Lie}^{\circ}$ (Prop. 1) and Lie ${ }^{\circ} \preccurlyeq \mathrm{Lie}^{*}$ (Prop. 1), then Lie $\preccurlyeq \mathrm{Lie}^{*}$. By Lem. 1, from Lie $\preccurlyeq$ Lie*$^{*}$ and $\mathrm{DI}_{=} \prec \succ$ Lie (Prop. 6), we get Lie* $\npreceq \mathrm{DI}_{=}$. The following example proves that $\mathrm{DI}_{=} \npreceq$ Lie $^{*}$ : Consider the three-dimensional vector field $\boldsymbol{p}=\left(x_{2},-x_{1}, 0\right)$. The invariance of the equation $x_{3}^{2}+\left(-1+x_{1}^{2}+x_{2}^{2}+x_{3}^{2}\right)^{2}=0$ cannot be established using Lie* ${ }^{*}$ the singular locus is a circle in $\mathbb{R}^{3}$ ), but is easily provable using $\mathrm{DI}_{=}$as $\mathfrak{L}_{\boldsymbol{p}}(h)$ vanishes.

Proposition 8. $\mathrm{DI}_{=} \prec \succ \mathrm{Lie}^{\circ}$.

Proof. By Lem. 1, from Lie $\preccurlyeq \operatorname{Lie}^{\circ}$ (Prop. 1) and $\mathrm{DI}_{=} \prec \succ$ Lie (Prop. 6), we get Lie $\npreceq \mathrm{DI}_{=}$. On the other hand, if $\mathrm{DI}_{=} \preccurlyeq \mathrm{Lie}^{\circ}$ then, by transitivity $\mathrm{DI}_{=} \preccurlyeq \mathrm{Lie}^{*}$ (since Lie $\preccurlyeq$ Lie$^{*}$ by Prop. 1 ), which contradicts $\mathrm{DI}_{=} \prec \succ \mathrm{Lie}^{*}$ (Prop. 7). Thus, $\mathrm{DI}_{=} \npreceq \mathrm{Lie}^{\circ}$, and the proposition follows.

Similarly, by substituting $\mathrm{DI}_{=}$by Lie, Lie* by P-c, and Lie ${ }^{\circ}$ by C-c in Prop. 7 and Prop. 8 as well as their respective proofs, we show that:

Proposition 9. Lie $\prec \succ$ P-c and Lie $\prec \succ$ C-c.

Proof. To complete the proof, we still need an example showing that Lie $\npreceq ~ P-c$. Consider the vector field $\boldsymbol{p}=\left(3\left(-4+x^{2}\right), 3+x y-y^{2}\right)$, the proof rule Lie fails to prove that the equation $h=-3+x^{2}+2 x y+6 y^{2}+2 x y^{3}+y^{4}=0$ is invariant as the singular locus of $h$ contains $(-2,1)$ and $(2,-1)$. However, $\mathfrak{L}_{\boldsymbol{p}}(h)=(6 x-4 y) h$ and therefore P-c proves that $h=0$ is an invariant equation.

The remaining cases follow from the results established above.

Proposition 10. For $d \in\{\mathrm{C}-\mathrm{c}, \mathrm{P}-\mathrm{c}\}, \ell \in\left\{\mathrm{Lie}^{\circ}, \mathrm{Lie}^{*}\right\}, d \prec \succ \ell$.

Proof. Since $\mathrm{DI}_{=} \prec d$, if $d \preccurlyeq \ell$, then $\mathrm{DI}_{=} \preccurlyeq \ell$. However, $\mathrm{DI}_{=} \prec \succ \ell$ (Prop. 7 and Prop. 8). Thus $d \npreceq \ell$. Similarly, since $l \succ$ Lie, if $d \succcurlyeq \ell$, then $d \succcurlyeq$ Lie which contradicts $d \prec \succ$ Lie (Prop. 9). Hence $d \nsucc \ell$ and the proposition follows. 
Remark 2. Provided the invariant candidate has no singular points, Lie's criterion is known to be both necessary and sufficient to prove invariance properties of level sets [21, Theorem 2.8]. Also, $\mathrm{DI}_{=}$characterizes invariant functions [25] but not all invariant equations. On the other hand, for algebraic differential equations, the differential radical criterion in DRI fully characterizes all invariant algebraic sets [11]. Thus, as established in Prop. 5, DRI increases the deductive power of both Darboux-based rules $\left\{\mathrm{DI}_{=}, \mathrm{C}-\mathrm{c}, \mathrm{P}-\mathrm{c}\right\}$ and Lie-based rules $\left\{\mathrm{Lie}, \mathrm{Lie}^{\circ}, \mathrm{Lie}^{*}\right\}$, which form different families.

\subsection{Complexity}

While decidable [31], the complexity of real quantifier elimination is doubly exponential in the number of quantifier alternations [7]. Most existing implementations of real quantifier elimination procedures are based on cylindrical algebraic decomposition (CAD) [3, 4], which has doublyexponential running time in the number of variables.

The purely existential fragment of real quantifier elimination has been shown to exhibit singly exponential time complexity in the number of variables [1]. However, in practice this has not yet led to an efficient decision procedure, so typically it is much more efficient to use CAD. Theoretically, the best bound on the complexity of deciding a sentence in the universal theory of $\mathbb{R}$ is given by $(s d)^{O(n)}$, where $s$ is the number of polynomials in the formula, $d$ their maximum degree and $n$ the number of variables [1].

The premises of rules $\mathrm{DI}_{=}$, Lie, $\mathrm{Lie}^{\circ}$, $\mathrm{Lie}^{*}$ are universally quantified sentences in the theory of real arithmetic. One sees from the expression for the complexity bound that it is important for these rules to keep the number of variables low and also that it is desirable to work with polynomials of low degree. In this respect, we would anticipate the rule Lie$^{*}$ to incur a performance penalty from introducing a fresh variable.

C-c and P-c involve reasoning about multivariate polynomial ideal membership, which is an EXPSPACE-complete problem over $\mathbb{Q}[19]$. Gröbner basis algorithms allow us to perform membership checks in ideals generated by multivariate polynomials. Significant advances have been made in algorithms for computing Gröbner bases [10] which in practice can be expected to perform very well.

The premise of DRI may be decided using a real quantifier elimination procedure, like any other first-order sentence in the theory of real arithmetic. However, in order to obtain the bound $N$ on the order of the Lie derivatives, one is also required to check for polynomial ideal membership at least $N-1$ times.

\section{Square-free Reduction}

In this section we assess the utility of performing square-free reduction of invariant candidates as a means of (i) increasing the deductive power of Lie-based proof rules and (ii) simplifying problems passed to decision procedures for real arithmetic. 


\subsection{Square-free Reduction with Lie-based Proof Rules}

While Lie uses a powerful criterion that captures a large class of practically relevant invariant sets, it will fail for some seemingly simple invariant candidates. For instance, the condition in the premise of Lie will not hold when the goal is to prove that $h=x^{2}-6 x+9=0$ is invariant, no matter what vector field one considers. The reason for this is simple: $x^{2}-6 x+9$ factorizes into $(x-3)^{2}$. The problem here lies in the polynomial $h$ itself, rather than the real variety $V_{\mathbb{R}}(h)$. In fact, $V_{\mathbb{R}}(h)$ is exactly the singular locus of $h$ and the proof rule Lie fails because all points inside $V_{\mathbb{R}}(h)$ are singular points. More generally, the chain rule implies $\nabla h^{k} \cdot \boldsymbol{p}=k h^{k-1} \nabla h \cdot \boldsymbol{p}$, which has the consequence that any polynomial $h$ which is not square-free will have vanishing gradient at the real roots of factors with multiplicity greater than 1 .

One can eliminate such annoying instances by reducing $h$ to square-free form, which is a basic pre-processing step used in computer algebra systems. The square-free reduction of a polynomial $h$ may be computed efficiently as follows:

$$
\mathrm{SF}(h)=\frac{h}{\operatorname{gcd}\left(h, \frac{\partial h}{\partial x_{1}}, \ldots, \frac{\partial h}{\partial x_{n}}\right)} .
$$

Intuitively, in performing square-free reduction we hope to shrink the singular locus of the original polynomial. If $\mathrm{SL}\left(\mathrm{SF}(h)\right.$ ) is the empty set (which is the case for $h=x^{2}-6 x+9$ in the example given above), the proof rule Lie applies to $\mathrm{SF}(h)$ but not to $h$. In general, $\mathrm{SF}(h)$ may satisfy the assumptions of the proof rules $\mathrm{Lie}^{\circ}$ or $\mathrm{Lie}^{*}$, where $h$ fails to do so. It is always sound to conclude that $h=0$ is invariant from the knowledge that $\mathrm{SF}(h)=0$ is invariant, since real varieties remain unaltered under square-free reduction of their defining polynomials [5], i.e. $V_{\mathbb{R}}(h) \equiv V_{\mathbb{R}}(\mathrm{SF}(h))$, thus replacing $h$ with $\mathrm{SF}(h)$ in the premise of Lie, $\mathrm{Lie}^{\circ}$ and $\mathrm{Lie}^{*}$ remains sound and enlarges the class of polynomials that these proof rules can work with.

Proposition 11. For all $\ell \in\left\{\mathrm{Lie}, \mathrm{Lie}^{\circ}, \mathrm{Lie}^{*}\right\}, \ell \prec \mathrm{SF} \ell$.

This result is unsurprising when one understands that Lie-based proof rules use geometric concepts to prove invariance properties of sets. In fact, the square-free reduction removes some purely algebraic oddities that prevent the geometric condition from holding true when checked syntactically by a machine.

In addition to increasing the deductive power, the square-free reduction reduces the total degree of the polynomial in the invariant candidate and hence serves to reduce the complexity of deciding the conditions in the premise (see Section 4.2). In our implementation, we adopt the convention that invariant candidates supplied to Lie and its generalizations are square-free reduced in a preprocessing step.

\subsection{Square-free Reduction with Darboux-based proof rules}

Unlike Lie-based proof rules, it is perhaps surprising that using square-free reduction as a preprocessing step for the proof rules $\mathrm{DI}_{=}$and $\mathrm{C}-\mathrm{c}$, denoted $\mathrm{SFDI}=$ and $\mathrm{SFC}-\mathrm{c}$ respectively, does not, in general, increase the deductive power. 
Proposition 12. $\mathrm{DI}_{=} \prec \succ \mathrm{SFDI}_{=}$.

Proof. (I) $\mathrm{DI}_{=} \nprec \mathrm{SFDI}_{=}$. The polynomial $h=x^{2} y$ is an invariant function for the vector field $\boldsymbol{p}=\left(\frac{\partial h}{\partial y},-\frac{\partial h}{\partial x}\right)=\left(x^{2},-2 x y\right)$, thus $\mathrm{DI}=$ proves the invariance of $h=0$. However, $\mathrm{SF}(h)$ is not an invariant function for the same vector field, since $\mathfrak{L}_{p}(\mathrm{SF}(h))=\mathfrak{L}_{p}(x y)=-x^{2} y \neq 0$, thus SFDI $=$ fails to prove the invariance of $h=0$. (II) $\mathrm{SFDI}_{=} \nprec \mathrm{DI}_{=}$. Similarly, the polynomial $h=x y$ is an invariant function for the vector field $\boldsymbol{p}=\left(\frac{\partial h}{\partial y},-\frac{\partial h}{\partial x}\right)=(x,-y)$, thus $\mathrm{SFDI}_{=}$proves the invariance of $x^{2} y=0$, since $\mathrm{SF}\left(x^{2} y\right)=h$. However, $\mathrm{DI}_{=}$fails to prove the invariance of $x^{2} y=0$, because $\mathfrak{L}_{p}\left(x^{2} y\right)=x^{2} y \neq 0$.

Prop. 12 may at first seem counter-intuitive. However, the criterion in the premise of $\mathrm{DI}_{=}$is different in that it proves that the candidate $h$ is an invariant function. In performing square-free reduction on $h$, one in general obtains a different function, $\mathrm{SF}(h)$, which need not be conserved in the system if $h$ is conserved or, conversely, may be conserved even if $h$ is not.

The same observation holds for C-c as the SF reduction does not preserve the constant rate exponential decrease (or increase).

Proposition 13. C-c $\prec \succ$ SFC-c.

Proof. (I) C-c $\nprec$ SFC-c. The proof rule C-c proves the invariance of $h=x^{2} y=0$ for the vector field $\boldsymbol{p}=\left(x^{2}, y(1-2 x)\right)$ as $\mathfrak{L}_{p}(h)=1 h$. However, C-c cannot prove $\mathrm{SF}(h)=0$, since $\mathfrak{L}_{p}(\mathrm{SF}(h))=\mathfrak{L}_{p}(x y)=(1-x) \mathrm{SF}(h)$. (II) SFC-c $\nprec$ C-c. For the same $h$, C-c proves the invariance of $\mathrm{SF}(h)=0$ for the vector field $\boldsymbol{p}=\left(x^{2}, y(1-x)\right)$ as $\mathfrak{L}_{p}(\mathrm{SF}(h))=\mathfrak{L}_{p}(x y)=$ $1 \mathrm{SF}(h)$. However, without the SF reduction C-c alone fails to prove the invariance of $h=0$ for the considered $\boldsymbol{p}$, as $\mathfrak{L}_{\boldsymbol{p}}(h)=(x+1) h$.

After Prop. 12 and 13, one expects P-c to be incomparable with its square-free counterpart. Surprisingly, the proof rules P-c and SFP-c (which applies P-c after the square-free reduction) are in fact equivalent. This follows from the fact that a polynomial is Darboux for a vector field $\boldsymbol{p}$ if and only if all its factors are also Darboux for the same vector field. Our findings are stated in Prop. 14 and its corollary Prop. 15.

Proposition 14. Let $h=q_{1}^{m_{1}} \cdots q_{r}^{m_{r}}$ denote the decomposition of the polynomial $h$ into irreducible (over the reals) factors, $q_{i}$. Then, $h$ is Darboux for $\boldsymbol{p}$ if and only if, for all $i, q_{i}$ is Darboux for $\boldsymbol{p}$.

Proof. If, for all $i$, the polynomial $q_{i}$ is Darboux for $\boldsymbol{p}$, then $q_{i}$ divides $\mathfrak{L}_{p}\left(q_{i}\right)$, i.e. $\frac{\mathfrak{S}_{p}\left(q_{i}\right)}{q_{i}} \in$ 
$\mathbb{R}\left[x_{1}, \ldots, x_{n}\right]$. Therefore, using the chain rule,

$$
\begin{aligned}
\mathfrak{L}_{p}(h) & =\mathfrak{L}_{p}\left(q_{1}^{m_{1}} \cdots q_{r}^{m_{r}}\right) \\
& =\sum_{i=1}^{r}\left(m_{i} \mathfrak{L}_{p}\left(q_{i}\right) q_{i}^{m_{i}-1} \prod_{j \neq i} q_{j}^{m_{j}}\right) \\
& =\sum_{i=1}^{r} m_{i} \mathfrak{L}_{p}\left(q_{i}\right) q_{i}^{m_{i}-1} \frac{h}{q_{i}^{m_{i}}} \\
& =h \sum_{i=1}^{r} m_{i} \frac{\mathfrak{L}_{p}\left(q_{i}\right)}{q_{i}} \\
& \in\langle h\rangle,
\end{aligned}
$$

and $h$ is also Darboux for $\boldsymbol{p}$.

If $h$ is Darboux for $\boldsymbol{p}$, then $h$ divides $\mathfrak{L}_{p}(h)$ and $\frac{\mathfrak{S}_{p}(h)}{h}$ is a polynomial. Recall that $\operatorname{SF}(h)=$ $q_{1} \cdots q_{r}$. Using Eq. (9), one gets

$$
\frac{\mathfrak{L}_{p}(h)}{h} \mathrm{SF}(h)=\sum_{i=1}^{r} m_{i} \frac{\mathfrak{L}_{p}\left(q_{i}\right)}{q_{i}} \mathrm{SF}(h) .
$$

For a fixed $i, q_{i}$ divides $\mathrm{SF}(h)$, it thus divides the left hand side of Eq. (11). Moreover, $q_{i}$ divides $\frac{\mathrm{SF}(h)}{q_{j}}$, for all $j \neq i$. It thus necessarily divides $m_{i} \frac{\operatorname{SF}(h)}{q_{i}} \mathfrak{L}_{p}\left(q_{i}\right)$. If $q_{i}$ divides $\frac{\operatorname{SF}(h)}{q_{i}}$, then there exists $j \neq i$ such that $q_{i}$ divides $q_{j}$, which contradicts the fact that all factors $q_{1}, \ldots, q_{r}$ are irreducible. Thus, $q_{i}$ divides $\mathfrak{L}_{p}\left(q_{i}\right)$ and $\mathfrak{L}_{p}\left(q_{i}\right) \in\left\langle q_{i}\right\rangle$.

Nota: Prop. 14 generalizes [9, Proposition 8.4] which states a similar result for 2-dimensional systems and polynomials over $\mathbb{C}$.

Proposition 15. P-c $\sim$ SFP-c.

Proof. The proof rule P-c proves the invariance of $h=0$ for $\boldsymbol{p}$ if and only if the polynomial $h$ is Darboux. However, by Prop. 14, $h$ is Darboux if and only if $\mathrm{SF}(h)$ is also Darboux. Therefore, SFP-c could be used equivalently to prove the invariance of $h=0$.

Remark 3. The condition $\mathfrak{L}_{p}(p) \in\langle\mathrm{SF}(p)\rangle$-which is weaker than $\mathfrak{L}_{p}(p) \in\langle p\rangle$-is not sufficient to prove the invariance of $p=0$. It is therefore an unsound proof rule. Consider the polynomial $p=\left(-1+x^{2}\right)^{2}$ and the 1-dimensional vector field $\dot{x}=x$. Although $\mathfrak{L}_{p}(p)=4\left(-1+x^{2}\right) x^{2} \in$ $\left\langle-1+x^{2}\right\rangle=\langle\mathrm{SF}(p)\rangle$, the equation $p=0$ is not invariant, however, because $x(t)= \pm e^{t}$. Notice that the proof rule $\mathrm{P}-\mathrm{c}$ (with or without the square-free reduction) is unable to prove or disprove the invariance of $p=0$.

\subsection{Square-free Reduction On Differential Radical Invariants (DRI)}

Square-free reduction cannot increase the deductive power of the proof rule DRI because its premise is necessary and sufficient to prove invariance of real algebraic sets, which is unaffected 
by applying SF reduction. However, the computational impact of using square-free reduction with DRI remains an interesting question. Empirically, we observed a better performance of DRI when the $\mathrm{SF}$ reduction is applied first. In addition to lowering the degrees of the involved polynomials (as it did for Lie-based proof rules), we observed that the order $N_{\mathrm{SF}}$ for $\mathrm{SF}(h)$ is always lower than the order $N$ for $h$. We, therefore, conjecture $N_{\mathrm{SF}} \leq N$. However, in Ex. 1 below, the square-free reduction resulted in a significant $(\times 100)$ computational overhead due to the ideal membership checking (which we perform using Gröbner bases with reverse lexicographic monomial ordering).

Example 1. Consider the following vector field $\boldsymbol{p}$ :

$$
\begin{aligned}
\dot{x_{1}} & =-24\left(x_{1}+x_{3}\right)\left(x_{3}^{6}-3 x_{1}^{2} x_{2}^{2} x_{3}^{2}+x_{1}^{2} x_{2}^{4}+x_{1}^{4} x_{2}^{2}\right) x_{4} x_{5}\left(x_{7}^{2}+x_{2}-12341\right)^{16}\left(x_{4} x_{5}^{2}-12 x_{6} x_{8}\right)^{11}, \\
\dot{x_{2}} & =144\left(x_{1}+x_{3}\right)\left(x_{3}^{6}-3 x_{1}^{2} x_{2}^{2} x_{3}^{2}+x_{1}^{2} x_{2}^{4}+x_{1}^{4} x_{2}^{2}\right)\left(x_{7}^{2}+x_{2}-12341\right)^{16} x_{8}\left(x_{4} x_{5}^{2}-12 x_{6} x_{8}\right)^{11}, \\
\dot{x_{3}} & =-32\left(x_{1}+x_{3}\right)\left(x_{3}^{6}-3 x_{1}^{2} x_{2}^{2} x_{3}^{2}+x_{1}^{2} x_{2}^{4}+x_{1}^{4} x_{2}^{2}\right) x_{7}\left(x_{7}^{2}+x_{2}-12341\right)^{15}\left(x_{4} x_{5}^{2}-12 x_{6} x_{8}\right)^{12}, \\
\dot{x_{4}} & =144\left(x_{1}+x_{3}\right)\left(x_{3}^{6}-3 x_{1}^{2} x_{2}^{2} x_{3}^{2}+x_{1}^{2} x_{2}^{4}+x_{1}^{4} x_{2}^{2}\right) x_{6}\left(x_{7}^{2}+x_{2}-12341\right)^{16}\left(x_{4} x_{5}^{2}-12 x_{6} x_{8}\right)^{11}, \\
\dot{x_{5}} & =\left(x_{1}+x_{3}\right)\left(2 x_{1} x_{2}^{4}+4 x_{1}^{3} x_{2}^{2}-6 x_{1} x_{3}^{2} x_{2}^{2}\right)\left(x_{4} x_{5}^{2}-12 x_{6} x_{8}\right)^{12}\left(x_{7}^{2}+x_{2}-12341\right)^{16} \\
& +\left(x_{3}^{6}-3 x_{1}^{2} x_{2}^{2} x_{3}^{2}+x_{1}^{2} x_{2}^{4}+x_{1}^{4} x_{2}^{2}\right)\left(x_{4} x_{5}^{2}-12 x_{6} x_{8}\right)^{12}\left(x_{7}^{2}+x_{2}-12341\right)^{16}, \\
\dot{x_{6}} & =\left(x_{1}+x_{3}\right)\left(2 x_{2} x_{1}^{4}+4 x_{2}^{3} x_{1}^{2}-6 x_{2} x_{3}^{2} x_{1}^{2}\right)\left(x_{4} x_{5}^{2}-12 x_{6} x_{8}\right)^{12}\left(x_{7}^{2}+x_{2}-12341\right)^{16} \\
& +16\left(x_{1}+x_{3}\right)\left(x_{3}^{6}-3 x_{1}^{2} x_{2}^{2} x_{3}^{2}+x_{1}^{2} x_{2}^{4}+x_{1}^{4} x_{2}^{2}\right)\left(x_{4} x_{5}^{2}-12 x_{6} x_{8}\right)^{12}\left(x_{7}^{2}+x_{2}-12341\right)^{15}, \\
\dot{x_{7}} & =\left(x_{1}+x_{3}\right)\left(6 x_{3}^{5}-6 x_{1}^{2} x_{2}^{2} x_{3}\right)\left(x_{4} x_{5}^{2}-12 x_{6} x_{8}\right)^{12}\left(x_{7}^{2}+x_{2}-12341\right)^{16} \\
& +\left(x_{3}^{6}-3 x_{1}^{2} x_{2}^{2} x_{3}^{2}+x_{1}^{2} x_{2}^{4}+x_{1}^{4} x_{2}^{2}\right)\left(x_{4} x_{5}^{2}-12 x_{6} x_{8}\right)^{12}\left(x_{7}^{2}+x_{2}-12341\right)^{16}, \\
\dot{x_{8}} & =12\left(x_{1}+x_{3}\right)\left(x_{3}^{6}-3 x_{1}^{2} x_{2}^{2} x_{3}^{2}+x_{1}^{2} x_{2}^{4}+x_{1}^{4} x_{2}^{2}\right) x_{5}^{2}\left(x_{7}^{2}+x_{2}-12341\right)^{16}\left(x_{4} x_{5}^{2}-12 x_{6} x_{8}\right)^{11},
\end{aligned}
$$

and let

$$
h=\left(x_{1}+x_{3}\right)\left(x_{3}^{6}-3 x_{1}^{2} x_{2}^{2} x_{3}^{2}+x_{1}^{2} x_{2}^{4}+x_{1}^{4} x_{2}^{2}\right)\left(x_{7}^{2}+x_{2}-12341\right)^{16}\left(x_{4} x_{5}^{2}-12 x_{6} x_{8}\right)^{12} .
$$

Attempting to prove that $h=0$ is invariant under the flow of this system using DRI we observe running time of under 2 seconds. Reducing $h$ to be square-free results in DRI running for over 8 minutes before it is able to prove the result. In this case, square-free reduction introduces a performance penalty when checking for polynomial ideal membership (which is performed using Gröbner bases with reverse lexicographic monomial ordering). We see that one needs to be careful when using square-free reduction with DRI because even though it is reasonable to expect better performance due to lower degrees in square-free reduced polynomials, performing this step may make the Gröbner basis computation more difficult for some problems.

In our implementation of DRI, called $\mathrm{DRI}_{\text {opt }}$ in the sequel, we use the square-free reduction only as a pre-processing step for the quantifier elimination problems in the premise of DRI.

Remark 4. Notice that Prop. 14 does not have an analogue for DRI. In other words, if a polynomial equation $h=0$ is invariant for $\boldsymbol{p}$, its irreducible factors need not define invariant equations themselves. Geometrically, this means that if a variety is invariant under the flow of $\boldsymbol{p}$, its irreducible components need not be invariants under the flow of p. For instance, consider the irreducible polynomials $q_{1}=y-1$ and $q_{2}=x^{2}+(y-1)^{2}$. The equation $q_{1} q_{2}=0$ which is equivalent to $y=1$, is invariant for $\boldsymbol{p}=(1,0)$, since the premise of the proof rule DRI holds true for $N=3$. However, the equation $q_{2}=0$, which is equivalent to $x=0 \wedge y=1$, is not an invariant equation for $\boldsymbol{p}$. 


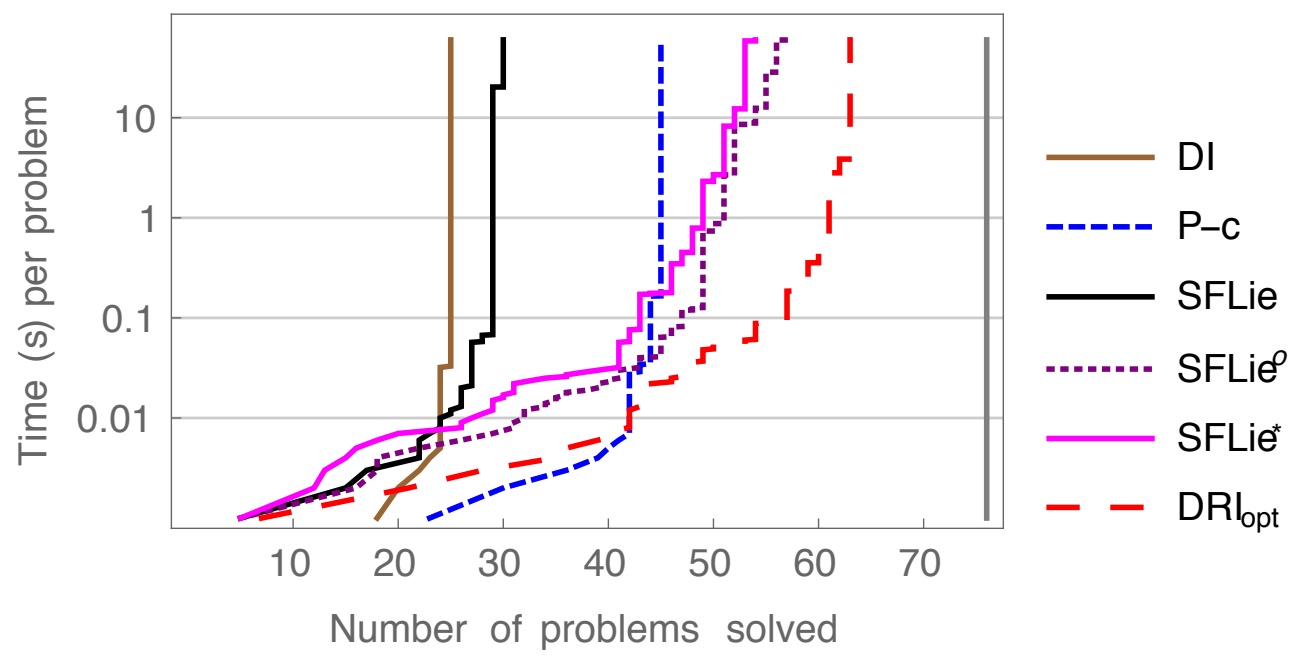

Figure 5: Experimental performance of proof rules: problems solved per time (log scale)

\section{Experimental Comparison}

We empirically compare the running time performance of all the proof rules discussed in this paper on a heterogeneous collection of 76 invariant varieties (see Appendix. A). The examples we used originate from a number of sources-many come from textbooks on Dynamical Systems; some from the literature on formal verification of hybrid systems; others have been hand-crafted to exploit sweetspots of certain proof rules. In this section, the prefix SF is implicit for all Lie-based proof rules. We consider 4 equally sized classes of invariant sets: (1) 24 smooth invariants, where Lie is both necessary and sufficient, (2) 17 isolated equilibria as trivial (for humans, not machines) equational invariants for which both $\mathrm{Lie}^{\circ}$ and Lie* provide necessary and sufficient conditions, (3) 17 other singularities and high integrals, (4) 18 functional invariants, where $\mathrm{DI}_{=}$is necessary and sufficient. The most interesting experimental question we seek to address here is whether the greater generality of the more deductively powerful proof rules also comes at a substantially higher computational cost when assessed across the entire spectrum of examples. As a complement to the theoretical deductive power relationships between the different proof rules (Section 4), we also seek to identify some nuances in the complexity of the conditions in the premises, which the coarse-grained complexity bounds miss, being highly sensitive to the number of variables.

From our experiments it emerges that the proof rules exhibit different (and at times surprising) trade-offs between generality and efficiency. Figure 5 compares the number of invariant varieties that each rule could prove within 60 seconds. The vertical axis shows cumulative time spent on the problems. All runs were performed on an Intel Core i5 $1.7 \mathrm{GHz}$ machine with 4Gb RAM. Generally, we observe DRI performing very well across the entire spectrum of problem classes. This is very encouraging, but also at first sight appears to defy intuition since it implies that one does not necessarily sacrifice performance when opting to use a more deductively powerful rule. In this graph, we also see that overall $\mathrm{Lie}^{\circ}$ appears to offer an interesting compromise between deductive power and efficiency - it is able to prove a significant body of problems that are out of scope for Lie, while avoiding the complexity penalty which affects Lie* (due to introducing an 

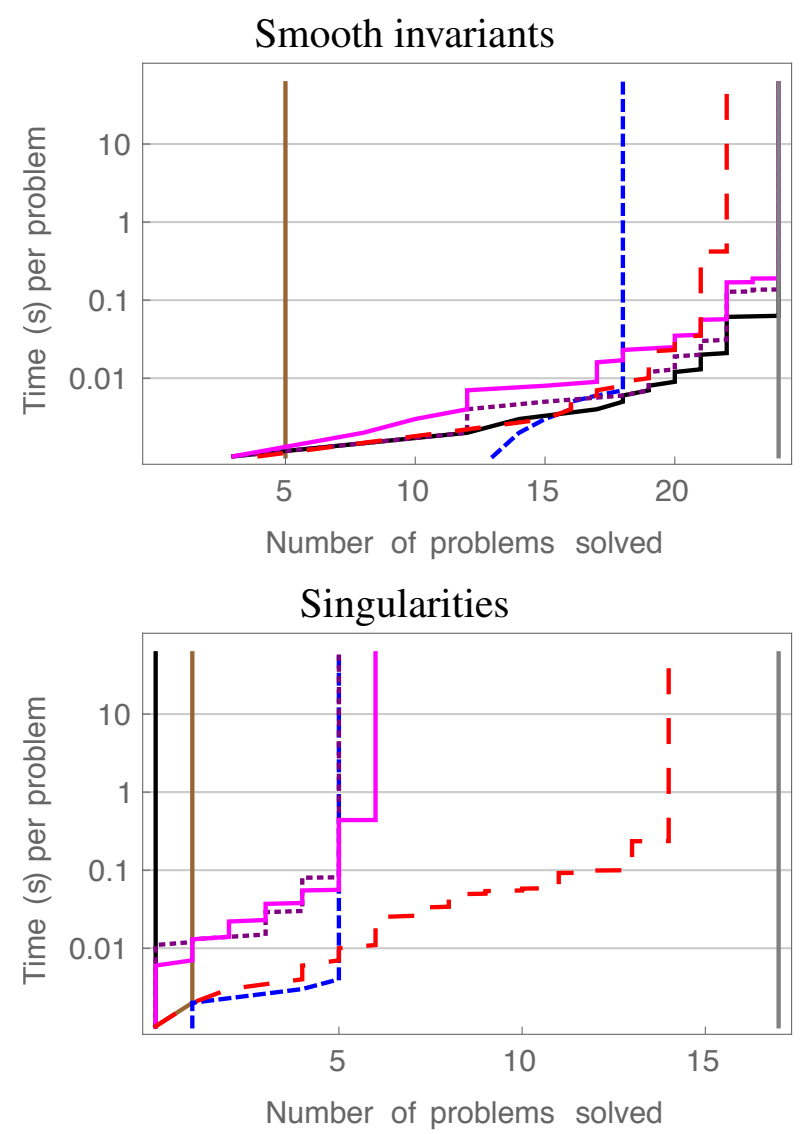

Isolated equilibria

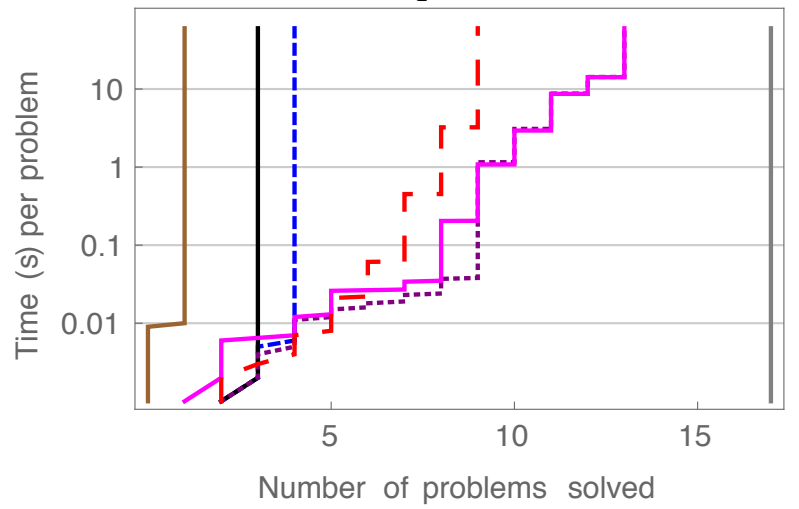

Functional invariants

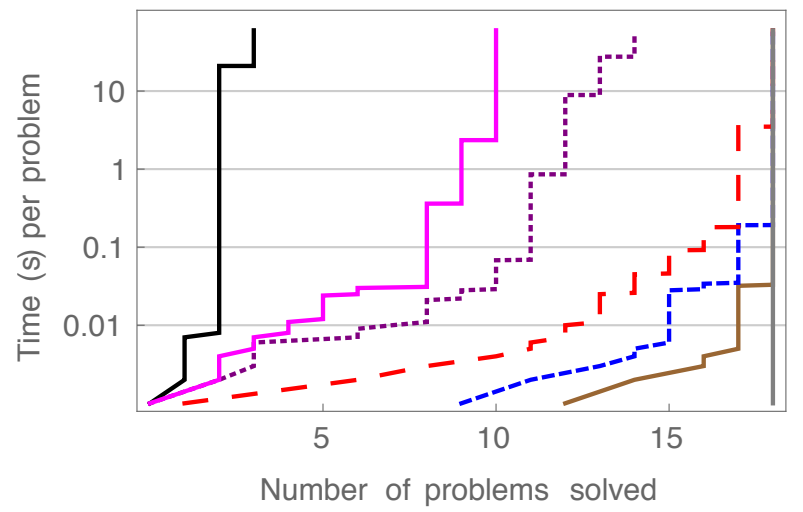

Figure 6: Number of problems solved per class (log scale).

extra variable).

A more careful analysis of the benchmarks reveals interesting relationships that are obscured in the "big picture"; to see them, one needs to consider the individual classes of invariants for which some of the sufficient conditions in the rules are in fact necessary and sufficient. Together with DRI, this yields two decision procedures for each class and allows us to focus only on running time performance and assess practicality of proof rules. In Fig. 6, we observe the rules $\operatorname{Lie}^{\circ}$ and $\mathrm{Lie}^{*}$ performing very well in proving invariance of isolated equilibria. This is to be expected as $\mathrm{Lie}^{\circ}$ in particular was formulated with this problem class in mind. It is interesting that DRI remains highly competitive here; though its performance is slightly poorer in our set of benchmarks.

It is clear that because proof rules $\mathrm{Lie}^{\circ}$ and $\mathrm{Lie}^{*}$ generalize Lie, they will be able to prove every problem in the smooth invariant benchmarks. The running time performance of the three rules is almost identical, with Lie offering a slight speed-up over its generalizations. The premises of $\mathrm{Lie}^{\circ}$ and $\mathrm{Lie}^{*}$ impose conditions on states in the singular locus, which is the empty set for smooth invariants; this, in practice, appears to be slightly more expensive than checking an equivalent property that the gradient is non-vanishing on the variety (as in the premise of Lie).

The proof rules $\mathrm{DI}_{=}$and $\mathrm{P}-\mathrm{c}$, corresponding to conditions with historical origins in the study of integrability of dynamical systems, can be seen to perform very well in proving functional invariants, while performing very poorly in benchmarks for isolated equilibria. In proofs of smooth 
invariants their behaviour is radically different, with $\mathrm{DI}_{=}$proving only a handful of examples and $\mathrm{P}-\mathrm{c}$ succeeding in proving most of the problems very efficiently. This can be explained by the fact that $\mathrm{P}$-c generalizes $\mathrm{DI}_{=}$and is therefore more deductively powerful. $\mathrm{P}$-c appears slightly slower at proving functional invariants, but shows very impressive running time performance for some problems from the smooth invariant benchmarks, where it is the fastest proof rule for many of problems where it succeeds. Comparing running time performance with DRI, we see that DRI is only slightly slower at proving functional invariants than $\mathrm{DI}=$ and $\mathrm{P}-\mathrm{c}$. Again, the performance gap between DRI and the two rules appears to be insignificant for most problems. Theoretically, when $\mathrm{P}-\mathrm{c}$ proves an invariant, DRI applies conditions that are identical to the premise of P-c. Hence, although DRI is a generalization, this does not come at a significant extra cost for the classes where $\mathrm{P}$-c shows good running time performance. The slightly greater running time of DRI compared to that of P-c can be accounted for by the fact that in our implementation DRI computes the Gröbner basis for every order $N$ including for $N=1$ where such computation is unnecessary.

For functional invariants $\mathrm{DI}_{=}$benefits from the fact that the condition in its premise, which requires to show that the Lie derivative evaluates to zero everywhere, is equivalent to showing that the Lie derivative is the zero polynomial, which can be checked very efficiently by symbolic computation, without a decision procedure for real arithmetic.

In the examples featuring singularities and high integrals in the benchmarks we see DRI as the clear winner, simply because there was no other rule that was tailored to work on this class. Indeed, the structure of these invariant sets can be rather involved, making it difficult to characterize in a single proof rule; however, sometimes it is possible to exploit the structure of high integrals inside a proof system and arrive at very efficient proofs that outperform DRI [12].

It is not surprising that DRI should overtake all the other rules in terms of deductive power (it is, after all, necessary and sufficient); what is remarkable is that the performance we observe for DRI is often very competitive to that of the sufficient rules when they also succeed at a proof. This observation suggests a possible strategy for proof search in a proof system: give precedence to DRI and switch to other sufficient rules if DRI takes longer than some time-out value. The rationale behind this decision is our empirical observation that DRI performs consistently well on all problem classes we considered, but it is also sometimes possible to save time by using a proof rule which is less deductively powerful. It is important to note here that the overall proof system benefits from including the sufficient proof rules, rather than relying solely upon DRI.

\section{Related Work}

TALY \& TIWARI in [30] investigate an approach to proving invariance properties of non-strict polynomial inequalities and closed semi-algebraic sets which inspired our formulation of the proof rules Lie $^{\circ}$ and Lie* for real algebraic varieties; we employ the same ideas for reasoning about the singular locus separately and appealing to the Nagumo theorem for the proof of soundness. At least some of the difficulties encountered with inequalities in [30] can be eliminated for real algebraic sets by working only with square-free reduced polynomials; a reduction we perform as a pre-processing step. Indeed, in [30] the authors provide a simple example in which an invariant polynomial equality is encoded as a polynomial inequality of the form $h^{2} \leq 0$ (over the reals this 
is equivalent to $h^{2}=0$ ) which falls out of scope of their proof rules. Square-free reduction may be extended to polynomial inequalities using order parity decomposition [8] and makes progress possible on similar problems.

The deductive power of the proof rule DI (which generalizes $\mathrm{DI}_{=}$to semi-algebraic sets) combined with other proof rules (such as differential cut or differential weakening) have been investigated in [26]. In this work, we focus on sound proof rules for checking invariance properties of algebraic sets and investigate their deductive power as well as their practical efficiency. To our knowledge, this is the first attempt to structure and empirically compare the performance of the proof rules we considered.

\section{Conclusions and Future Work}

We have theoretically and empirically compared proof rules for checking invariance properties of real algebraic sets in polynomial vector fields. Our work investigated an important aspect of deductive safety verification of continuous and hybrid dynamical systems. Namely, given the abundance of existing sufficient conditions for invariant equations ( $\mathrm{DI}_{=}, \mathrm{C}-\mathrm{c}$ and $\left.\mathrm{P}-\mathrm{c}, \mathrm{Lie}\right)$, in addition to the extensions of Lie's criterion, $\mathrm{Lie}^{\circ}$ and $\mathrm{Lie}^{*}$, and the recently developed necessary and sufficient conditions for real algebraic invariants (DRI [11]), it is crucial to know whether the gains in deductive power come at the price of greater computational complexity and poor running time performance that would hinder practical applications. The work presented in this paper leads us to arrive at the following conclusions:

- Empirically, we observe that the most deductively powerful rule (DRI) performs very well in checking invariance of polynomial equalities.

- P-c is made redundant by DRI (DRI strictly increases the deductive power of P-c while being equally efficient).

- Reducing polynomials to square-free form is always of benefit to the proof rule Lie and its generalizations, where it yields improvements in both the deductive power and the running time performance.

- We proved that combining $\mathrm{SF}$ with the proof rules $\mathrm{DI}_{=}$and $\mathrm{C}$-c yields new incomparable proof rules, whereas SF with P-c is as powerful as P-c alone.

- Performing square-free reduction of an invariant candidate may introduce a performance penalty for DRI and therefore cannot be regarded as an optimization.

It is our hope to extend this work to similarly study proof methods for invariance of semialgebraic sets in polynomial vector fields. This problem is of fundamental importance to verification of continuous and hybrid systems [22,24] and a better understanding of the factors affecting proof rule efficiency has the potential to be of considerable practical utility. There are currently three available methods that have been proposed for checking invariance of semi-algebraic sets: the method of differential invariants due to Platzer [27], a characterization of invariant semi-algebraic 
sets due to Liu et al. [17] and a method for closed semi-algebraic sets based on the Nagumo theorem proposed by Taly \& Tiwari [30]. The latter approach can unfortunately be shown to be unsound (we identify the problem in Appendix. B); however, this deficiency can be fixed. It would be very interesting to extend the work presented in this paper to investigate the relationship between deductive power and running time performance in the aforementioned methods. We leave this for future work.

Acknowledgments The authors would like to thank Dr. Ashish Tiwari at SRI International for his kind and informative response to our technical queries and extend special thanks to Dr. Paul B. Jackson at the LFCS, University of Edinburgh, for his valuable help in improving the manuscript.

\section{References}

[1] S. Basu, R. Pollack, and M.-F. Roy. On the combinatorial and algebraic complexity of quantifier elimination. J. ACM, 43(6):1002-1045, 1996.

[2] F. Blanchini and S. Miani. Set-Theoretic Methods in Control. Systems \& Control : Foundations \& Applications. Birkhäuser, 2008.

[3] G. E. Collins. Hauptvortrag: Quantifier elimination for real closed fields by cylindrical algebraic decomposition. In Automata Theory and Formal Languages, volume 33 of LNCS, pages 134-183. Springer, 1975.

[4] G. E. Collins and H. Hong. Partial cylindrical algebraic decomposition for quantifier elimination. J. Symb. Comput., 12(3):299-328, Sept. 1991.

[5] D. A. Cox, J. Little, and D. O'Shea. Ideals, Varieties, and Algorithms - an introduction to computational algebraic geometry and commutative algebra (2. ed.). Springer, 1997.

[6] J.-G. Darboux. Mémoire sur les équations différentielles algébriques du premier ordre et du premier degré. Bulletin des Sciences Mathématiques et Astronomiques, 2(1):151-200, 1878.

[7] J. H. Davenport and J. Heintz. Real quantifier elimination is doubly exponential. J. Symb. Comput., 5(1/2):29-35, 1988.

[8] A. Dolzmann and T. Sturm. Simplification of quantifier-free formulas over ordered fields. Journal of Symbolic Computation, 24:209-231, 1995.

[9] F. Dumortier, J. Llibre, and J. C. Artés. Qualitative Theory of Planar Differential Systems. Springer, 2006.

[10] J. C. Faugère. A new efficient algorithm for computing Gröbner bases without reduction to zero (F5). In ISSAC, pages 75-83, New York, NY, USA, 2002. ACM. 
[11] K. Ghorbal and A. Platzer. Characterizing algebraic invariants by differential radical invariants. In TACAS, volume 8413, pages 279-294. Springer, 2014.

[12] K. Ghorbal, A. Sogokon, and A. Platzer. Invariance of conjunctions of polynomial equalities for algebraic differential equations. In SAS, volume 8723 of $L N C S$, pages 151-167. Springer, 2014.

[13] K. Ghorbal, A. Sogokon, and A. Platzer. A hierarchy of proof rules for checking differential invariance of algebraic sets. In VMCAI, volume 8931 of $L N C S$, pages 431-448. Springer, 2015.

[14] A. Goriely. Integrability and Nonintegrability of Dynamical Systems. Advanced series in nonlinear dynamics. World Scientific, 2001.

[15] S. Lie. Vorlesungen über continuierliche Gruppen mit Geometrischen und anderen Anwendungen. Teubner, Leipzig, 1893.

[16] E. Lindelöf. Sur l'application de la méthode des approximations successives aux équations différentielles ordinaires du premier ordre. Comptes rendus hebdomadaires des séances de l'Académie des sciences, 116:454-458, 1894.

[17] J. Liu, N. Zhan, and H. Zhao. Computing semi-algebraic invariants for polynomial dynamical systems. In EMSOFT, pages 97-106. ACM, 2011.

[18] N. Matringe, A. V. Moura, and R. Rebiha. Generating invariants for non-linear hybrid systems by linear algebraic methods. In $S A S$, volume 6337 of $L N C S$, pages 373-389. Springer, 2010.

[19] E. W. Mayr. Membership in polynomial ideals over Q is exponential space complete. In B. Monien and R. Cori, editors, STACS, volume 349 of LNCS, pages 400-406. Springer, 1989.

[20] M. Nagumo. Über die Lage der Integralkurven gewöhnlicher Differentialgleichungen (in German). In Proceedings of the Physico-Mathematical Society of Japan, volume 24, pages 551-559, May 1942.

[21] P. J. Olver. Applications of Lie Groups to Differential Equations. Springer, 2000.

[22] A. Platzer. Differential dynamic logic for hybrid systems. J. Autom. Reasoning, 41(2):143189, 2008.

[23] A. Platzer. Differential-algebraic dynamic logic for differential-algebraic programs. J. Log. Comput., 20(1):309-352, 2010.

[24] A. Platzer. The complete proof theory of hybrid systems. In LICS, pages 541-550. IEEE, 2012.

[25] A. Platzer. A differential operator approach to equational differential invariants - (invited paper). In ITP, volume 7406 of $L N C S$, pages 28-48. Springer, 2012. 
[26] A. Platzer. The structure of differential invariants and differential cut elimination. Logical Methods in Computer Science, 8(4):1-38, 2012.

[27] A. Platzer and E. M. Clarke. Computing differential invariants of hybrid systems as fixedpoints. In $C A V$, volume 5123 of $L N C S$, pages 176-189. Springer, 2008.

[28] D. Richardson. Some undecidable problems involving elementary functions of a real variable. Journal of Symbolic Logic, 33(4):514-520, 121968.

[29] S. Sankaranarayanan, H. B. Sipma, and Z. Manna. Constructing invariants for hybrid systems. Form. Methods Syst. Des., 32(1):25-55, 2008.

[30] A. Taly and A. Tiwari. Deductive verification of continuous dynamical systems. In FSTTCS, volume 4 of LIPICs, pages 383-394, 2009.

[31] A. Tarski. A decision method for elementary algebra and geometry. Bull. Amer. Math. Soc., 59, 1951.

[32] A. Tiwari. Abstractions for hybrid systems. Form. Methods Syst. Des., 32(1):57-83, 2008.

[33] W. Walter. Ordinary Differential Equations. Springer New York, 1998.

[34] Z. Wu. Tangent cone and contingent cone to the intersection of two closed sets. Nonlinear Analysis: Theory, Methods \& Applications , 73(5):1203 - 1220, 2010. 


\section{A Appendix. Benchmark tables}

This section presents the benchmarks used to evaluate the performance of the proof rules. The dimension of the vector field is given under Dim in the tables below. Also shown are the polynomial degree of the invariant candidate $d$. Inv and the degree of the vector field $d$. VF defined as the maximum degree of all the polynomials $p_{i}$. Times are shown in seconds. True means that the proof rule was able to prove the invariance of the candidate, otherwise it prints $\perp$ (except for DRI which prints False as it is necessary and sufficient). The time out is set to $60 \mathrm{~s}$ per rule per problem.

\section{Smooth Invariants (Regular Varieties)}

\begin{tabular}{|c|c|c|c|c|c|c|c|c|c|c|c|}
\hline Prob. & Dim & d. Inv & $\mathrm{d} . \mathrm{VF}$ & $\mathrm{DI}$ & $P-C$ & SFLie & SFLie ${ }^{\circ}$ & SFLie* & $\mathrm{DRI}_{\mathrm{opt}}$ & & \\
\hline 1 & 1 & 5 & 1 & $\begin{array}{l}0.001 \\
\pm\end{array}$ & $\begin{array}{l}0.001 \\
+\end{array}$ & $\begin{array}{l}0.002 \\
\text { True }\end{array}$ & $\begin{array}{l}0.002 \\
\text { True }\end{array}$ & $\begin{array}{l}0.004 \\
\text { True }\end{array}$ & $\begin{array}{l}0.005 \\
\text { True }\end{array}$ & $(\mathrm{N}=3)$ & \\
\hline 2 & 1 & 21 & 1 & $\begin{array}{l}0.002 \\
\pm\end{array}$ & $\begin{array}{l}0.003 \\
+\end{array}$ & $\begin{array}{l}0.001 \\
\text { True }\end{array}$ & $\begin{array}{l}0.001 \\
\text { True }\end{array}$ & $\begin{array}{l}0.003 \\
\text { True }\end{array}$ & $\begin{array}{l}0.035 \\
\text { True }\end{array}$ & $(\mathrm{N}=11$ & \\
\hline 3 & 2 & 6 & 1 & $\begin{array}{l}0.003 \\
+\end{array}$ & $\begin{array}{l}0.002 \\
\pm\end{array}$ & $\begin{array}{l}0.004 \\
\text { True }\end{array}$ & $\begin{array}{l}0.005 \\
\text { True }\end{array}$ & $\begin{array}{l}0.008 \\
\text { True }\end{array}$ & $\begin{array}{l}0.023 \\
\text { True }\end{array}$ & $(\mathrm{N}=5)$ & \\
\hline 4 & 2 & 22 & 1 & $\begin{array}{l}0.006 \\
\pm\end{array}$ & $\begin{array}{l}0.006 \\
+\end{array}$ & $\begin{array}{l}0.004 \\
\text { True }\end{array}$ & $\begin{array}{l}0.005 \\
\text { True }\end{array}$ & $\begin{array}{l}0.007 \\
\text { True }\end{array}$ & $\begin{array}{l}0.419 \\
\text { True }\end{array}$ & $(\mathrm{N}=21$ & \\
\hline 5 & 4 & 14 & 1 & $\begin{array}{l}0.093 \\
\pm\end{array}$ & $\begin{array}{l}0.074 \\
+\end{array}$ & $\begin{array}{l}0.062 \\
\text { True }\end{array}$ & $\begin{array}{l}0.128 \\
\text { True }\end{array}$ & $\begin{array}{l}0.169 \\
\text { True }\end{array}$ & $\begin{array}{l}>60 \mathrm{~s} \\
\text { rimeou }\end{array}$ & & \\
\hline 6 & 4 & 32 & 1 & $\begin{array}{l}0.725 \\
\pm\end{array}$ & $\begin{array}{l}0.985 \\
+\end{array}$ & $\begin{array}{l}0.062 \\
\text { True }\end{array}$ & $\begin{array}{l}0.137 \\
\text { True }\end{array}$ & $\begin{array}{l}0.190 \\
\text { True }\end{array}$ & $\begin{array}{l}>60 \mathrm{~s} \\
\text { Timeou }\end{array}$ & & \\
\hline 7 & 2 & 2 & 1 & $\begin{array}{l}0.000 \times 10^{-3} \\
\perp\end{array}$ & $\begin{array}{l}0.000 \times 10^{-3} \\
\text { True }\end{array}$ & $\begin{array}{l}0.000 \times 10^{-3} \\
\text { True }\end{array}$ & $\begin{array}{l}0.000 \times 10^{-3} \\
\text { True }\end{array}$ & $\begin{array}{l}0.000 \times 10^{-3} \\
\text { True }\end{array}$ & $\begin{array}{l}0.002 \\
\text { True }\end{array}$ & $(\mathrm{N}=1)$ & \\
\hline 8 & 2 & 2 & 1 & $\begin{array}{l}0.000 \times 10^{-3} \\
\text { True }\end{array}$ & $\begin{array}{l}0.000 \times 10^{-3} \\
\text { True }\end{array}$ & $\begin{array}{l}0.002 \\
\text { True }\end{array}$ & $\begin{array}{l}0.002 \\
\text { True }\end{array}$ & $\begin{array}{l}0.002 \\
\text { True }\end{array}$ & $\begin{array}{l}0.000 \times \\
\text { True }\end{array}$ & $\times 10^{-3}$ & $(\mathrm{~N}=1)$ \\
\hline 9 & 3 & 1 & 1 & $\begin{array}{l}0.000 \times 10^{-3} \\
\text { True }\end{array}$ & $\begin{array}{l}0.000 \times 10^{-3} \\
\text { True }\end{array}$ & $\begin{array}{l}0.000 \times 10^{-3} \\
\text { True }\end{array}$ & $\begin{array}{l}0.000 \times 10^{-3} \\
\text { True }\end{array}$ & $\begin{array}{l}0.000 \times 10^{-3} \\
\text { True }\end{array}$ & $\begin{array}{l}0.000 \times \\
\text { True }\end{array}$ & $\times 10^{-3}$ & $(\mathrm{~N}=1)$ \\
\hline 10 & 2 & 1 & 5 & $\begin{array}{l}0.002 \\
\pm\end{array}$ & $\begin{array}{l}0.000 \times 10^{-3} \\
\text { True }\end{array}$ & $\begin{array}{l}0.002 \\
\text { True }\end{array}$ & $\begin{array}{l}0.002 \\
\text { True }\end{array}$ & $\begin{array}{l}0.002 \\
\text { True }\end{array}$ & $\begin{array}{l}0.001 \\
\text { True }\end{array}$ & $(\mathrm{N}=1)$ & \\
\hline 11 & 2 & 2 & 3 & $\begin{array}{l}0.002 \\
\pm\end{array}$ & $\begin{array}{l}0.002 \\
\text { True }\end{array}$ & $\begin{array}{l}0.004 \\
\text { True }\end{array}$ & $\begin{array}{l}0.006 \\
\text { True }\end{array}$ & $\begin{array}{l}0.008 \\
\text { True }\end{array}$ & $\begin{array}{l}0.002 \\
\text { True }\end{array}$ & $(\mathrm{N}=1)$ & \\
\hline 12 & 2 & 6 & 5 & $\begin{array}{l}0.000 \times 10^{-3} \\
\text { True }\end{array}$ & $\begin{array}{l}0.000 \times 10^{-3} \\
\text { True }\end{array}$ & $\begin{array}{l}0.006 \\
\text { True }\end{array}$ & $\begin{array}{l}0.006 \\
\text { True }\end{array}$ & $\begin{array}{l}0.023 \\
\text { True }\end{array}$ & $\begin{array}{l}0.002 \\
\text { True }\end{array}$ & $(\mathrm{N}=1)$ & \\
\hline 13 & 3 & 2 & 4 & $\begin{array}{l}0.026 \\
+\end{array}$ & $\begin{array}{l}0.003 \\
\text { True }\end{array}$ & $\begin{array}{l}0.008 \\
\text { True }\end{array}$ & $\begin{array}{l}0.012 \\
\text { True }\end{array}$ & $\begin{array}{l}0.024 \\
\text { True }\end{array}$ & $\begin{array}{l}0.004 \\
\text { True }\end{array}$ & $(\mathrm{N}=1)$ & \\
\hline 14 & 4 & 2 & 4 & $\begin{array}{l}0.079 \\
+\end{array}$ & $\begin{array}{l}0.006 \\
\text { True }\end{array}$ & $\begin{array}{l}0.013 \\
\text { True }\end{array}$ & $\begin{array}{l}0.019 \\
\text { True }\end{array}$ & $\begin{array}{l}0.036 \\
\text { True }\end{array}$ & $\begin{array}{l}0.009 \\
\text { True }\end{array}$ & $(\mathrm{N}=1)$ & \\
\hline 15 & 5 & 2 & 4 & $\begin{array}{l}0.669 \\
\pm\end{array}$ & $\begin{array}{l}0.007 \\
\text { True }\end{array}$ & $\begin{array}{l}0.020 \\
\text { True }\end{array}$ & $\begin{array}{l}0.031 \\
\text { True }\end{array}$ & $\begin{array}{l}0.056 \\
\text { True }\end{array}$ & $\begin{array}{l}0.008 \\
\text { True }\end{array}$ & $(\mathrm{N}=1)$ & \\
\hline 16 & 3 & 2 & 3 & $\begin{array}{l}0.000 \times 10^{-3} \\
\text { True }\end{array}$ & $\begin{array}{l}0.000 \times 10^{-3} \\
\text { True }\end{array}$ & $\begin{array}{l}0.000 \times 10^{-3} \\
\text { True }\end{array}$ & $\begin{array}{l}0.000 \times 10^{-3} \\
\text { True }\end{array}$ & $\begin{array}{l}0.000 \times 10^{-3} \\
\text { True }\end{array}$ & $\begin{array}{l}0.001 \\
\text { True }\end{array}$ & $(\mathrm{N}=1)$ & \\
\hline 17 & 3 & 2 & 3 & $\begin{array}{l}0.002 \\
\pm\end{array}$ & $\begin{array}{l}0.000 \times 10^{-3} \\
\text { True }\end{array}$ & $\begin{array}{l}0.003 \\
\text { True }\end{array}$ & $\begin{array}{l}0.004 \\
\text { True }\end{array}$ & $\begin{array}{l}0.008 \\
\text { True }\end{array}$ & $\begin{array}{l}0.002 \\
\text { True }\end{array}$ & $(\mathrm{N}=1)$ & \\
\hline 18 & 2 & 4 & 2 & $\begin{array}{l}0.005 \\
+\end{array}$ & $\begin{array}{l}0.002 \\
\text { True }\end{array}$ & $\begin{array}{l}0.005 \\
\text { True }\end{array}$ & $\begin{array}{l}0.006 \\
\text { True }\end{array}$ & $\begin{array}{l}0.016 \\
\text { True }\end{array}$ & $\begin{array}{l}0.003 \\
\text { True }\end{array}$ & $(\mathrm{N}=1)$ & \\
\hline 19 & 2 & 2 & 2 & $\begin{array}{l}0.000 \times 10^{-3} \\
\perp\end{array}$ & $\begin{array}{l}0.000 \times 10^{-3} \\
\text { True }\end{array}$ & $\begin{array}{l}0.002 \\
\text { True }\end{array}$ & $\begin{array}{l}0.002 \\
\text { True }\end{array}$ & $\begin{array}{l}0.004 \\
\text { True }\end{array}$ & $\begin{array}{l}0.001 \\
\text { True }\end{array}$ & $(\mathrm{N}=1)$ & \\
\hline 20 & 2 & 1 & 3 & $\begin{array}{l}0.000 \times 10^{-3} \\
\perp\end{array}$ & $\begin{array}{l}0.000 \times 10^{-3} \\
\text { True }\end{array}$ & $\begin{array}{l}0.001 \\
\text { True }\end{array}$ & $\begin{array}{l}0.001 \\
\text { True }\end{array}$ & $\begin{array}{l}0.001 \\
\text { True }\end{array}$ & $\begin{array}{l}0.000 \times \\
\text { True }\end{array}$ & $\times 10^{-3}$ & $(\mathrm{~N}=1)$ \\
\hline 21 & 2 & 1 & 2 & $\begin{array}{l}0.002 \\
+\end{array}$ & $\begin{array}{l}0.000 \times 10^{-3} \\
\text { True }\end{array}$ & $\begin{array}{l}0.002 \\
\text { True }\end{array}$ & $\begin{array}{l}0.002 \\
\text { True }\end{array}$ & $\begin{array}{l}0.002 \\
\text { True }\end{array}$ & $\begin{array}{l}0.001 \\
\text { True }\end{array}$ & $(\mathrm{N}=1)$ & \\
\hline 22 & 2 & 1 & 2 & $\begin{array}{l}0.001 \\
\pm\end{array}$ & $\begin{array}{l}0.000 \times 10^{-3} \\
\text { True }\end{array}$ & $\begin{array}{l}0.001 \\
\text { True }\end{array}$ & $\begin{array}{l}0.002 \\
\text { True }\end{array}$ & $\begin{array}{l}0.002 \\
\text { True }\end{array}$ & $\begin{array}{l}0.001 \\
\text { True }\end{array}$ & $(\mathrm{N}=1)$ & \\
\hline 23 & 2 & 1 & 2 & $\begin{array}{l}0.000 \times 10^{-3} \\
\perp\end{array}$ & $\begin{array}{l}0.000 \times 10^{-3} \\
\text { True }\end{array}$ & $\begin{array}{l}0.001 \\
\text { True }\end{array}$ & $\begin{array}{l}0.001 \\
\text { True }\end{array}$ & $\begin{array}{l}0.001 \\
\text { True }\end{array}$ & $\begin{array}{l}0.000 \times \\
\text { True }\end{array}$ & $\times 10^{-3}$ & $(\mathrm{~N}=1)$ \\
\hline 24 & 6 & 2 & 2 & $\begin{array}{l}0.000 \times 10^{-3} \\
\text { True }\end{array}$ & $\begin{array}{l}0.000 \times 10^{-3} \\
\text { True }\end{array}$ & $\begin{array}{l}0.002 \\
\text { True }\end{array}$ & $\begin{array}{l}0.005 \\
\text { True }\end{array}$ & $\begin{array}{l}0.007 \\
\text { True }\end{array}$ & $\begin{array}{l}0.002 \\
\text { True }\end{array}$ & $(\mathrm{N}=1)$ & \\
\hline
\end{tabular}




\section{Isolated Equilibria}

\begin{tabular}{|c|c|c|c|c|c|c|c|c|c|c|}
\hline Prob. & Dim & d. Inv & $\mathrm{d} \cdot \mathrm{VF}$ & DI & $\mathrm{P}-\mathrm{C}$ & SFLie & SFLie ${ }^{\circ}$ & SFLie* & $\mathrm{DRI} I_{\text {opt }}$ & \\
\hline 1 & 2 & 18 & 17 & $\begin{array}{l}0.009 \\
\text { True }\end{array}$ & $\begin{array}{l}0.005 \\
\text { True }\end{array}$ & $\begin{array}{l}0.019 \\
\pm\end{array}$ & $\begin{array}{l}0.037 \\
\text { True }\end{array}$ & $\begin{array}{l}0.204 \\
\text { True }\end{array}$ & $\begin{array}{l}0.007 \\
\text { True } \quad(\mathrm{N}=1)\end{array}$ & \\
\hline 2 & 1 & 1 & 1 & $\begin{array}{l}0.000 \times 10^{-3} \\
\pm\end{array}$ & $\begin{array}{l}0.000 \times 10^{-3} \\
\text { True }\end{array}$ & $\begin{array}{l}0.000 \times 10^{-3} \\
\text { True }\end{array}$ & $\begin{array}{l}0.000 \times 10^{-3} \\
\text { True }\end{array}$ & $\begin{array}{l}0.000 \times 10^{-3} \\
\text { True }\end{array}$ & $\begin{array}{l}0.000 \times 10^{-3} \\
\text { True }\end{array}$ & $(\mathrm{N}=1)$ \\
\hline 3 & 1 & 2 & 3 & $\begin{array}{l}0.000 \times 10^{-3} \\
\perp\end{array}$ & $\begin{array}{l}0.000 \times 10^{-3} \\
\text { True }\end{array}$ & $\begin{array}{l}0.000 \times 10^{-3} \\
\text { True }\end{array}$ & $\begin{array}{l}0.000 \times 10^{-3} \\
\text { True }\end{array}$ & $\begin{array}{l}0.001 \\
\text { True }\end{array}$ & $\begin{array}{l}0.000 \times 10^{-3} \\
\text { True }\end{array}$ & $(\mathrm{N}=1)$ \\
\hline 4 & 1 & 2 & 3 & $0.000 \times 10^{-3}$ & $\begin{array}{l}0.001 \\
\pm\end{array}$ & $\begin{array}{l}0.002 \\
\text { True }\end{array}$ & $\begin{array}{l}0.002 \\
\text { True }\end{array}$ & $\begin{array}{l}0.006 \\
\text { True }\end{array}$ & $\begin{array}{l}0.003 \\
\text { True } \quad(\mathrm{N}=2)\end{array}$ & \\
\hline 5 & 2 & 2 & 2 & $\begin{array}{l}0.004 \\
+\end{array}$ & $\begin{array}{l}0.002 \\
\text { True }\end{array}$ & $\begin{array}{l}0.004 \\
\pm\end{array}$ & $\begin{array}{l}0.005 \\
\text { True }\end{array}$ & $\begin{array}{l}0.006 \\
\text { True }\end{array}$ & $\begin{array}{l}0.002 \\
\text { True } \quad(\mathrm{N}=1)\end{array}$ & \\
\hline 6 & 2 & 46 & 4 & $\begin{array}{l}34.470 \\
+\end{array}$ & $\begin{array}{l}0.016 \\
\pm\end{array}$ & $\begin{array}{l}>60 \mathrm{~s} \\
\text { Himeout }\end{array}$ & $\begin{array}{l}>60 \mathrm{~s} \\
\text { rimeout }\end{array}$ & $\begin{array}{l}>60 \mathrm{~s} \\
\text { rimeout }\end{array}$ & $\begin{array}{l}0.451 \\
\text { True } \quad(\mathrm{N}=3)\end{array}$ & \\
\hline 7 & 3 & 2 & 243 & $\begin{array}{l}>60 \mathrm{~s} \\
\text { Mimeout }\end{array}$ & $\begin{array}{l}0.057 \\
\pm\end{array}$ & $\begin{array}{l}0.023 \\
\pm\end{array}$ & $\begin{array}{l}14.260 \\
\text { True }\end{array}$ & $\begin{array}{l}14.180 \\
\text { True }\end{array}$ & $\begin{array}{l}>60 \mathrm{~s} \\
\text { rimeout }\end{array}$ & \\
\hline 8 & 2 & 128 & 5 & $\begin{array}{l}0.429 \\
+\end{array}$ & $\begin{array}{l}0.050 \\
\pm\end{array}$ & $\begin{array}{l}0.004 \\
\pm\end{array}$ & $\begin{array}{l}0.012 \\
\text { True }\end{array}$ & $\begin{array}{l}0.013 \\
\text { True }\end{array}$ & $\begin{array}{l}>60 \mathrm{~s} \\
\text { rimeout }\end{array}$ & \\
\hline 9 & 3 & 2 & 2 & $\begin{array}{l}0.009 \\
+\end{array}$ & $\begin{array}{l}0.002 \\
\pm\end{array}$ & $\begin{array}{l}0.018 \\
\pm\end{array}$ & $\begin{array}{l}0.016 \\
\text { True }\end{array}$ & $\begin{array}{l}0.026 \\
\text { True }\end{array}$ & $\begin{array}{l}0.062 \\
\text { True } \quad(\mathrm{N}=4)\end{array}$ & \\
\hline 10 & 3 & 25 & 2 & $\begin{array}{l}>60 \mathrm{~s} \\
\text { rimeout }\end{array}$ & $\begin{array}{l}0.007 \\
\pm\end{array}$ & $\begin{array}{l}>60 \mathrm{~s} \\
\text { Timeout }\end{array}$ & $\begin{array}{l}>60 \mathrm{~s} \\
\text { Mimeout }\end{array}$ & $\begin{array}{l}>60 \mathrm{~s} \\
\text { rimeout }\end{array}$ & $\begin{array}{l}>60 \mathrm{~s} \\
\text { Timeout }\end{array}$ & \\
\hline 11 & 3 & 2 & 90 & $\begin{array}{l}>60 \mathrm{~s} \\
\text { rimeout }\end{array}$ & $\begin{array}{l}0.068 \\
+\end{array}$ & $\begin{array}{l}0.032 \\
\pm\end{array}$ & $\begin{array}{l}1.153 \\
\text { True }\end{array}$ & $\begin{array}{l}1.082 \\
\text { True }\end{array}$ & $\begin{array}{l}3.233 \\
\text { True } \quad(\mathrm{N}=3)\end{array}$ & \\
\hline 12 & 4 & 2 & 4 & $\begin{array}{l}0.717 \\
\perp\end{array}$ & $\begin{array}{l}0.003 \\
\pm\end{array}$ & $\begin{array}{l}0.014 \\
+\end{array}$ & $\begin{array}{l}3.084 \\
\text { True }\end{array}$ & $\begin{array}{l}2.940 \\
\text { True }\end{array}$ & $\begin{array}{l}>60 \mathrm{~s} \\
\text { rimeout }\end{array}$ & \\
\hline 13 & 4 & 2 & 2 & $\begin{array}{l}0.030 \\
+\end{array}$ & $\begin{array}{l}0.005 \\
\pm\end{array}$ & $\begin{array}{l}0.020 \\
\pm\end{array}$ & $\begin{array}{l}0.019 \\
\text { True }\end{array}$ & $\begin{array}{l}0.035 \\
\text { True }\end{array}$ & $\begin{array}{l}0.021 \\
\text { True }\end{array} \quad(\mathrm{N}=2)$ & \\
\hline 14 & 4 & 2 & 2 & $\begin{array}{l}0.002 \\
+\end{array}$ & $\begin{array}{l}0.002 \\
\pm\end{array}$ & $\begin{array}{l}0.019 \\
\pm\end{array}$ & $\begin{array}{l}0.023 \\
\text { True }\end{array}$ & $\begin{array}{l}0.027 \\
\text { True }\end{array}$ & $\begin{array}{l}>60 \mathrm{~s} \\
\text { Timeout }\end{array}$ & \\
\hline 15 & 5 & 2 & 6 & $\begin{array}{l}0.204 \\
+\end{array}$ & $\begin{array}{l}0.007 \\
+\end{array}$ & $\begin{array}{l}0.016 \\
\pm\end{array}$ & $\begin{array}{l}8.739 \\
\text { True }\end{array}$ & $\begin{array}{l}8.674 \\
\text { True }\end{array}$ & $\begin{array}{l}>60 \mathrm{~s} \\
\text { rimeout }\end{array}$ & \\
\hline 16 & 5 & 12 & 3 & $\begin{array}{l}0.757 \\
\perp\end{array}$ & $\begin{array}{l}0.013 \\
+\end{array}$ & $\begin{array}{l}>60 \mathrm{~s} \\
\text { Timeout }\end{array}$ & $\begin{array}{l}>60 \mathrm{~s} \\
\text { Mimeout }\end{array}$ & $\begin{array}{l}>60 \mathrm{~s} \\
\text { Mimeout }\end{array}$ & $\begin{array}{l}>60 \mathrm{~s} \\
\text { Mimeout }\end{array}$ & \\
\hline 17 & 5 & 2 & 35 & $\begin{array}{l}>60 \mathrm{~s} \\
\text { inimeout }\end{array}$ & $\begin{array}{l}1.754 \\
\perp\end{array}$ & $\begin{array}{l}0.026 \\
\pm\end{array}$ & $\begin{array}{l}>60 \mathrm{~s} \\
\text { Mimeout }\end{array}$ & $\begin{array}{l}>60 \mathrm{~s} \\
\text { Mimeout }\end{array}$ & $\begin{array}{l}>60 \mathrm{~s} \\
\text { Mimeout }\end{array}$ & \\
\hline
\end{tabular}


Other Singularities

\begin{tabular}{|c|c|c|c|c|c|c|c|c|c|c|}
\hline Prob. & Dim & d. Inv & $\mathrm{d} \cdot \mathrm{VF}$ & $\mathrm{DI}$ & $\mathrm{P}-\mathrm{C}$ & SFLie & SFLie & SFLie ${ }^{*}$ & $\mathrm{DRI} I_{\text {opt }}$ & \\
\hline 1 & 2 & 6 & 2 & $\begin{array}{l}0.013 \\
\pm\end{array}$ & $\begin{array}{l}0.005 \\
\pm\end{array}$ & $\begin{array}{l}0.023 \\
\pm\end{array}$ & $\begin{array}{l}0.029 \\
\text { True }\end{array}$ & $\begin{array}{l}0.438 \\
\text { True }\end{array}$ & $\begin{array}{l}0.054 \\
\text { True }\end{array}$ & $(\mathrm{N}=3)$ \\
\hline 2 & 2 & 4 & 3 & $\begin{array}{l}0.006 \\
\pm\end{array}$ & $\begin{array}{l}0.004 \\
\text { True }\end{array}$ & $\begin{array}{l}0.009 \\
\pm\end{array}$ & $\begin{array}{l}0.014 \\
\text { True }\end{array}$ & $\begin{array}{l}0.022 \\
\text { True }\end{array}$ & $\begin{array}{l}0.003 \\
\text { True }\end{array}$ & $(\mathrm{N}=1)$ \\
\hline 3 & 3 & 6 & 10 & $\begin{array}{l}0.016 \\
\pm\end{array}$ & $\begin{array}{l}0.006 \\
\perp\end{array}$ & $\begin{array}{l}0.081 \\
\perp\end{array}$ & $\begin{array}{l}0.081 \\
\text { True }\end{array}$ & $\begin{array}{l}>60 \mathrm{~s} \\
\text { rimeout }\end{array}$ & $\begin{array}{l}>60 \mathrm{~s} \\
\text { Timeout }\end{array}$ & \\
\hline 4 & 3 & 4 & 3 & $\begin{array}{l}0.010 \\
\pm\end{array}$ & $\begin{array}{l}0.007 \\
\perp\end{array}$ & $\begin{array}{l}0.067 \\
\perp\end{array}$ & $\begin{array}{l}0.072 \\
\perp\end{array}$ & $\begin{array}{l}0.468 \\
\perp\end{array}$ & $\begin{array}{l}0.049 \\
\text { True }\end{array}$ & $(\mathrm{N}=3)$ \\
\hline 5 & 3 & 4 & 3 & $\begin{array}{l}0.004 \\
\pm\end{array}$ & $\begin{array}{l}0.003 \\
\perp\end{array}$ & $\begin{array}{l}0.015 \\
\pm\end{array}$ & $\begin{array}{l}0.017 \\
\perp\end{array}$ & $\begin{array}{l}0.043 \\
\perp\end{array}$ & $\begin{array}{l}0.026 \\
\text { True }\end{array}$ & $(\mathrm{N}=3)$ \\
\hline 6 & 3 & 4 & 1 & $\begin{array}{l}0.004 \\
\pm\end{array}$ & $\begin{array}{l}0.002 \\
\pm\end{array}$ & $\begin{array}{l}0.016 \\
\pm\end{array}$ & $\begin{array}{l}0.017 \\
\pm\end{array}$ & $\begin{array}{l}0.025 \\
\pm\end{array}$ & $\begin{array}{l}0.092 \\
\text { True }\end{array}$ & $(\mathrm{N}=5)$ \\
\hline 7 & 7 & 14 & 1 & $\begin{array}{l}0.003 \\
\perp\end{array}$ & $\begin{array}{l}0.002 \\
\text { True }\end{array}$ & $\begin{array}{l}0.007 \\
\perp\end{array}$ & $\begin{array}{l}0.007 \\
\perp\end{array}$ & $\begin{array}{l}0.007 \\
\text { True }\end{array}$ & $\begin{array}{l}0.002 \\
\text { True }\end{array}$ & $(\mathrm{N}=1)$ \\
\hline 8 & 2 & 4 & 2 & $\begin{array}{l}0.005 \\
\pm\end{array}$ & $\begin{array}{l}0.003 \\
\text { True }\end{array}$ & $\begin{array}{l}0.007 \\
\pm\end{array}$ & $\begin{array}{l}0.011 \\
\text { True }\end{array}$ & $\begin{array}{l}0.037 \\
\text { True }\end{array}$ & $\begin{array}{l}0.004 \\
\text { True }\end{array}$ & $(\mathrm{N}=1)$ \\
\hline 9 & 2 & 4 & 2 & $\begin{array}{l}0.013 \\
+\end{array}$ & $\begin{array}{l}0.003 \\
\text { True }\end{array}$ & $\begin{array}{l}0.015 \\
\pm\end{array}$ & $\begin{array}{l}0.030 \\
\pm\end{array}$ & $\begin{array}{l}0.056 \\
\text { True }\end{array}$ & $\begin{array}{l}0.007 \\
\text { True }\end{array}$ & $(\mathrm{N}=1)$ \\
\hline 10 & 3 & 4 & 3 & $\begin{array}{l}0.005 \\
\pm\end{array}$ & $\begin{array}{l}0.004 \\
\pm\end{array}$ & $\begin{array}{l}0.031 \\
\pm\end{array}$ & $\begin{array}{l}0.033 \\
\perp\end{array}$ & $\begin{array}{l}0.055 \\
\pm\end{array}$ & $\begin{array}{l}0.034 \\
\text { True }\end{array}$ & $(\mathrm{N}=2)$ \\
\hline 11 & 3 & 6 & 2 & $\begin{array}{l}0.001 \\
\pm\end{array}$ & $\begin{array}{l}0.001 \\
\pm\end{array}$ & $\begin{array}{l}0.017 \\
\pm\end{array}$ & $\begin{array}{l}0.030 \\
\perp\end{array}$ & $\begin{array}{l}0.049 \\
\perp\end{array}$ & $\begin{array}{l}0.010 \\
\text { True }\end{array}$ & $(\mathrm{N}=2)$ \\
\hline 12 & 5 & 6 & 2 & $\begin{array}{l}0.003 \\
+\end{array}$ & $\begin{array}{l}0.002 \\
\pm\end{array}$ & $\begin{array}{l}0.080 \\
+\end{array}$ & $\begin{array}{l}0.168 \\
\pm\end{array}$ & $\begin{array}{l}>60 \mathrm{~s} \\
\text { rimeout }\end{array}$ & $\begin{array}{l}0.058 \\
\text { True }\end{array}$ & $(\mathrm{N}=2)$ \\
\hline 13 & 9 & 18 & 8 & $\begin{array}{l}0.013 \\
\pm\end{array}$ & $\begin{array}{l}0.023 \\
\pm\end{array}$ & $\begin{array}{l}>60 \mathrm{~s} \\
\text { rimeout }\end{array}$ & $\begin{array}{l}>60 \mathrm{~s} \\
\text { rimeout }\end{array}$ & $\begin{array}{l}>60 \mathrm{~s} \\
\text { rimeout }\end{array}$ & $\begin{array}{l}>60 \mathrm{~s} \\
\text { Timeout }\end{array}$ & \\
\hline 14 & 5 & 4 & 4 & $\begin{array}{l}0.096 \\
+\end{array}$ & $\begin{array}{l}0.020 \\
\pm\end{array}$ & $\begin{array}{l}0.071 \\
\pm\end{array}$ & $\begin{array}{l}0.228 \\
\pm\end{array}$ & $\begin{array}{l}>60 \mathrm{~s} \\
\text { rimeout }\end{array}$ & $\begin{array}{l}>60 \mathrm{~s} \\
\text { Mimeout }\end{array}$ & \\
\hline 15 & 9 & 10 & 4 & $\begin{array}{l}0.009 \\
+\end{array}$ & $\begin{array}{l}0.010 \\
\pm\end{array}$ & $\begin{array}{l}0.708 \\
\pm\end{array}$ & $\begin{array}{l}0.511 \\
\pm\end{array}$ & $\begin{array}{l}>60 \mathrm{~s} \\
\text { Himeout }\end{array}$ & $\begin{array}{l}0.235 \\
\text { True }\end{array}$ & $(\mathrm{N}=2)$ \\
\hline 16 & 3 & 4 & 3 & $\begin{array}{l}0.006 \\
\pm\end{array}$ & $\begin{array}{l}0.003 \\
\pm\end{array}$ & $\begin{array}{l}0.020 \\
\pm\end{array}$ & $\begin{array}{l}0.027 \\
\pm\end{array}$ & $\begin{array}{l}0.050 \\
\pm\end{array}$ & $\begin{array}{l}0.100 \\
\text { True }\end{array}$ & $(\mathrm{N}=5)$ \\
\hline 17 & 6 & 2 & 2 & $\begin{array}{l}0.001 \\
\text { True }\end{array}$ & $\begin{array}{l}0.000 \times 10^{-3} \\
\text { True }\end{array}$ & $\begin{array}{l}0.005 \\
\pm\end{array}$ & $\begin{array}{l}0.014 \\
\text { True }\end{array}$ & $\begin{array}{l}0.014 \\
\text { True }\end{array}$ & $\begin{array}{l}0.002 \\
\text { True }\end{array}$ & $(\mathrm{N}=1)$ \\
\hline
\end{tabular}




\section{Conserved Quantities (Functional Invariants)}

\begin{tabular}{|c|c|c|c|c|c|c|c|c|c|c|}
\hline Prob. & Dim & d.Inv & d. VF & DI & $\mathrm{P}-\mathrm{C}$ & SFLie & SFLie ${ }^{\circ}$ & SFLie* & $\mathrm{DR} I_{\mathrm{opt}}$ & \\
\hline 1 & 2 & 3 & 2 & $\begin{array}{l}0.000 \times 10^{-3} \\
\text { True }\end{array}$ & $\begin{array}{l}0.000 \times 10^{-3} \\
\text { True }\end{array}$ & $\begin{array}{l}0.004 \\
\perp\end{array}$ & $\begin{array}{l}0.002 \\
\text { True }\end{array}$ & $\begin{array}{l}0.007 \\
\text { True }\end{array}$ & $\begin{array}{l}0.001 \\
\text { True }\end{array}$ & $(\mathrm{N}=1)$ \\
\hline 2 & 2 & 6 & 5 & $\begin{array}{l}0.000 \times 10^{-3} \\
\text { True }\end{array}$ & $\begin{array}{l}0.000 \times 10^{-3} \\
\text { True }\end{array}$ & $\begin{array}{l}0.007 \\
+\end{array}$ & $\begin{array}{l}0.007 \\
\text { True }\end{array}$ & $\begin{array}{l}2.350 \\
\text { True }\end{array}$ & $\begin{array}{l}0.002 \\
\text { True }\end{array}$ & $(\mathrm{N}=1)$ \\
\hline 3 & 2 & 6 & 5 & $\begin{array}{l}0.002 \\
\text { True }\end{array}$ & $\begin{array}{l}0.001 \\
\text { True }\end{array}$ & $\begin{array}{l}0.008 \\
+\end{array}$ & $\begin{array}{l}0.009 \\
\text { True }\end{array}$ & $\begin{array}{l}0.030 \\
\text { True }\end{array}$ & $\begin{array}{l}0.002 \\
\text { True }\end{array}$ & $(\mathrm{N}=1)$ \\
\hline 4 & 2 & 4 & 1 & $\begin{array}{l}0.000 \times 10^{-3} \\
\text { True }\end{array}$ & $\begin{array}{l}0.000 \times 10^{-3} \\
\text { True }\end{array}$ & $\begin{array}{l}0.014 \\
\perp\end{array}$ & $\begin{array}{l}0.014 \\
\perp\end{array}$ & $\begin{array}{l}0.026 \\
\perp\end{array}$ & $\begin{array}{l}0.003 \\
\text { True }\end{array}$ & $(\mathrm{N}=1)$ \\
\hline 5 & 4 & 3 & 2 & $\begin{array}{l}0.000 \times 10^{-3} \\
\text { True }\end{array}$ & $\begin{array}{l}0.000 \times 10^{-3} \\
\text { True }\end{array}$ & $\begin{array}{l}0.009 \\
\perp\end{array}$ & $\begin{array}{l}0.006 \\
\text { True }\end{array}$ & $\begin{array}{l}0.031 \\
\text { True }\end{array}$ & $\begin{array}{l}0.003 \\
\text { True }\end{array}$ & $(\mathrm{N}=1)$ \\
\hline 6 & 3 & 6 & 10 & $\begin{array}{l}0.002 \\
\text { True }\end{array}$ & $\begin{array}{l}0.002 \\
\text { True }\end{array}$ & $\begin{array}{l}0.028 \\
+\end{array}$ & $\begin{array}{l}0.021 \\
\text { True }\end{array}$ & $\begin{array}{l}>60 \mathrm{~s} \\
\text { pimeout }\end{array}$ & $\begin{array}{l}0.005 \\
\text { True }\end{array}$ & $(\mathrm{N}=1)$ \\
\hline 7 & 4 & 2 & 1 & $\begin{array}{l}0.001 \\
\text { True }\end{array}$ & $\begin{array}{l}0.000 \times 10^{-3} \\
\text { True }\end{array}$ & $\begin{array}{l}0.001 \\
\text { True }\end{array}$ & $\begin{array}{l}0.002 \\
\text { True }\end{array}$ & $\begin{array}{l}0.002 \\
\text { True }\end{array}$ & $\begin{array}{l}0.002 \\
\text { True }\end{array}$ & $(\mathrm{N}=1)$ \\
\hline 8 & 4 & 12 & 11 & $\begin{array}{l}0.000 \times 10^{-3} \\
\text { True }\end{array}$ & $\begin{array}{l}0.000 \times 10^{-3} \\
\text { True }\end{array}$ & $\begin{array}{l}0.010 \\
\perp\end{array}$ & $\begin{array}{l}0.006 \\
\text { True }\end{array}$ & $\begin{array}{l}0.025 \\
\text { True }\end{array}$ & $\begin{array}{l}0.003 \\
\text { True }\end{array}$ & $(\mathrm{N}=1)$ \\
\hline 9 & 8 & 12 & 11 & $\begin{array}{l}0.005 \\
\text { True }\end{array}$ & $\begin{array}{l}0.003 \\
\text { True }\end{array}$ & $\begin{array}{l}0.007 \\
\text { True }\end{array}$ & $\begin{array}{l}0.011 \\
\text { True }\end{array}$ & $\begin{array}{l}0.011 \\
\text { True }\end{array}$ & $\begin{array}{l}0.007 \\
\text { True }\end{array}$ & $(\mathrm{N}=1)$ \\
\hline 10 & 8 & 9 & 8 & $\begin{array}{l}0.003 \\
\text { True }\end{array}$ & $\begin{array}{l}0.003 \\
\text { True }\end{array}$ & $\begin{array}{l}>60 \mathrm{~s} \\
\text { rimeout }\end{array}$ & $\begin{array}{l}0.069 \\
\text { True }\end{array}$ & $\begin{array}{l}>60 \mathrm{~s} \\
\text { rimeout }\end{array}$ & $\begin{array}{l}0.011 \\
\text { True }\end{array}$ & $(\mathrm{N}=1)$ \\
\hline 11 & 8 & 75 & 74 & $\begin{array}{l}0.000 \times 10^{-3} \\
\text { True }\end{array}$ & $\begin{array}{l}0.192 \\
\text { True }\end{array}$ & $\begin{array}{l}>60 \mathrm{~s} \\
\text { Mimeout }\end{array}$ & $\begin{array}{l}>60 \mathrm{~s} \\
\text { Mimeout }\end{array}$ & $\begin{array}{l}>60 \mathrm{~s} \\
\text { Mimeout }\end{array}$ & $\begin{array}{l}3.498 \\
\text { True }\end{array}$ & $(\mathrm{N}=1)$ \\
\hline 12 & 8 & 31 & 30 & $\begin{array}{l}0.000 \times 10^{-3} \\
\text { True }\end{array}$ & $\begin{array}{l}0.006 \\
\text { True }\end{array}$ & $\begin{array}{l}12.710 \\
\perp\end{array}$ & $\begin{array}{l}>60 \mathrm{~s} \\
\text { rimeout }\end{array}$ & $\begin{array}{l}>60 \mathrm{~s} \\
\text { Timeout }\end{array}$ & $\begin{array}{l}0.091 \\
\text { True }\end{array}$ & $(\mathrm{N}=1)$ \\
\hline 13 & 8 & 29 & 28 & $\begin{array}{l}0.000 \times 10^{-3} \\
\text { True }\end{array}$ & $\begin{array}{l}0.003 \\
\text { True }\end{array}$ & $\begin{array}{l}7.917 \\
+\end{array}$ & $\begin{array}{l}8.896 \\
\text { True }\end{array}$ & $\begin{array}{l}>60 \mathrm{~s} \\
\text { Timeout }\end{array}$ & $\begin{array}{l}0.025 \\
\text { True }\end{array}$ & $(\mathrm{N}=1)$ \\
\hline 14 & 8 & 18 & 17 & $\begin{array}{l}0.032 \\
\text { True }\end{array}$ & $\begin{array}{l}0.029 \\
\text { True }\end{array}$ & $\begin{array}{l}1.463 \\
+\end{array}$ & $\begin{array}{l}0.857 \\
\text { True }\end{array}$ & $\begin{array}{l}>60 \mathrm{~s} \\
\text { rimeout }\end{array}$ & $\begin{array}{l}0.045 \\
\text { True }\end{array}$ & $(\mathrm{N}=1)$ \\
\hline 15 & 8 & 5 & 4 & $\begin{array}{l}0.000 \times 10^{-3} \\
\text { True }\end{array}$ & $\begin{array}{l}0.000 \times 10^{-3} \\
\text { True }\end{array}$ & $\begin{array}{l}>60 \mathrm{~s} \\
\text { rimeout }\end{array}$ & $\begin{array}{l}0.029 \\
\text { True }\end{array}$ & $\begin{array}{l}0.362 \\
\text { True }\end{array}$ & $\begin{array}{l}0.003 \\
\text { True }\end{array}$ & $(\mathrm{N}=1)$ \\
\hline 16 & 8 & 16 & 15 & $\begin{array}{l}0.000 \times 10^{-3} \\
\text { True }\end{array}$ & $\begin{array}{l}0.035 \\
\text { True }\end{array}$ & $\begin{array}{l}20.980 \\
\text { True }\end{array}$ & $\begin{array}{l}27.560 \\
\text { True }\end{array}$ & $\begin{array}{l}>60 \mathrm{~s} \\
\text { rimeout }\end{array}$ & $\begin{array}{l}0.180 \\
\text { True }\end{array}$ & $(\mathrm{N}=1)$ \\
\hline 17 & 3 & 2 & 1 & $\begin{array}{l}0.000 \times 10^{-3} \\
\text { True }\end{array}$ & $\begin{array}{l}0.000 \times 10^{-3} \\
\text { True }\end{array}$ & $\begin{array}{l}0.001 \\
\perp\end{array}$ & $\begin{array}{l}0.001 \\
\text { True }\end{array}$ & $\begin{array}{l}0.002 \\
\text { True }\end{array}$ & $\begin{array}{l}0.000 \times \\
\text { True }\end{array}$ & $10^{-3}$ \\
\hline 18 & 7 & 6 & 1 & $\begin{array}{l}0.000 \times 10^{-3} \\
\text { True }\end{array}$ & $\begin{array}{l}0.000 \times 10^{-3} \\
\text { True }\end{array}$ & $\begin{array}{l}0.006 \\
\perp\end{array}$ & $\begin{array}{l}0.006 \\
\pm\end{array}$ & $\begin{array}{l}0.005 \\
\text { True }\end{array}$ & $\begin{array}{l}0.001 \\
\text { True }\end{array}$ & $(\mathrm{N}=1)$ \\
\hline
\end{tabular}




\section{B Appendix. Fixing Unsoundness in [30]}

In this section we give a simple example that highlights a soundness issue in the method for proving invariance of closed semi-algebraic sets reported in [30]. We will require an additional definition, which we give below.

Definition 7 (Contingent cone). Given a set $S \subseteq X$ and a state $\boldsymbol{x} \in X$, the contingent cone to $S$ at $\boldsymbol{x}$ is defined as the set of all vectors $\boldsymbol{v} \in \mathbb{R}^{n}$ that are sub-tangent to $S$ at $\boldsymbol{x}$. Formally, we write

$$
K_{S}(\boldsymbol{x}) \equiv\left\{\boldsymbol{v} \in \mathbb{R}^{n} \mid \liminf _{t \rightarrow 0^{+}} \frac{\operatorname{dist}(S, \boldsymbol{x}+t \boldsymbol{v})}{t}=0\right\} .
$$

The contingent cone has special properties that can, in practice, present challenges. In particular, one needs to be very careful when constructing the contingent cone for a conjunctive set in terms of the contingent cones for the individual conjuncts.

Proposition 16. Let $S_{1}, S_{2} \subseteq X$, then in general

$$
K_{S_{1}}(\boldsymbol{x}) \cap K_{S_{2}}(\boldsymbol{x}) \nsubseteq K_{S_{1} \cap S_{2}}(\boldsymbol{x}) .
$$

Proof. Consider the case where $X=\mathbb{R}^{2}, S_{1} \equiv\left\{\boldsymbol{x} \mid x_{2}+x_{1}^{2} \leq 0\right\}$ and $S_{2} \equiv\left\{\boldsymbol{x} \mid x_{2}-x_{1}^{2} \geq 0\right\}$. The two sets intersect at $0 \in X$. At the origin, the contingent cones for the conjuncts are given by two half-planes $K_{S_{1}}(\mathbf{0}) \equiv\left\{\boldsymbol{x} \mid x_{2} \leq 0\right\}$ and $K_{S_{2}}(\mathbf{0}) \equiv\left\{\boldsymbol{x} \mid x_{2} \geq 0\right\}$; the intersection of the contingent cones is given by the real $x_{2}$ line, i.e. $K_{S_{1}} \cap K_{S_{2}}=\left\{\boldsymbol{x} \mid x_{2}=0\right\}$, whereas the contingent cone to the intersection of the two sets is given by the zero vector, $K_{S_{1} \cap S_{2}}=\{\mathbf{0}\}$.

This property is the cause of unsoundness in the approach to proving invariance of closed semialgebraic sets reported in [30, p. 393, lifting to formulas with boolean connectives]. By applying Nagumo's sub-tangency criterion to each conjunct restricted to the conjunction one is showing $\boldsymbol{p}(\boldsymbol{x}) \in K_{S_{1}}(\boldsymbol{x}) \cap K_{S_{2}}(\boldsymbol{x})$ for all $\boldsymbol{x} \in S_{1} \cap S_{2}$. With this, one concludes that the origin is positively invariant under the vector field $\boldsymbol{p}(\boldsymbol{x})$, corresponding to the system $\dot{x}_{1}=1, \dot{x}_{2}=0$ in the example from the above proof, which is patently not the case. One can remove this source of unsoundness by taking into account closure properties of the contingent cone; in particular, one needs to impose extra conditions that will guarantee the inclusion

$$
K_{S_{1}}(\boldsymbol{x}) \cap K_{S_{2}}(\boldsymbol{x}) \subseteq K_{S_{1} \cap S_{2}}(\boldsymbol{x})
$$

Various methods exist for ensuring this property (see e.g. [34]) and it is thus possible to remove the source of unsoundness in [30]. In [2], the authors defined practical sets in a way that encodes one possible sufficient condition for ensuring the inclusion above. 


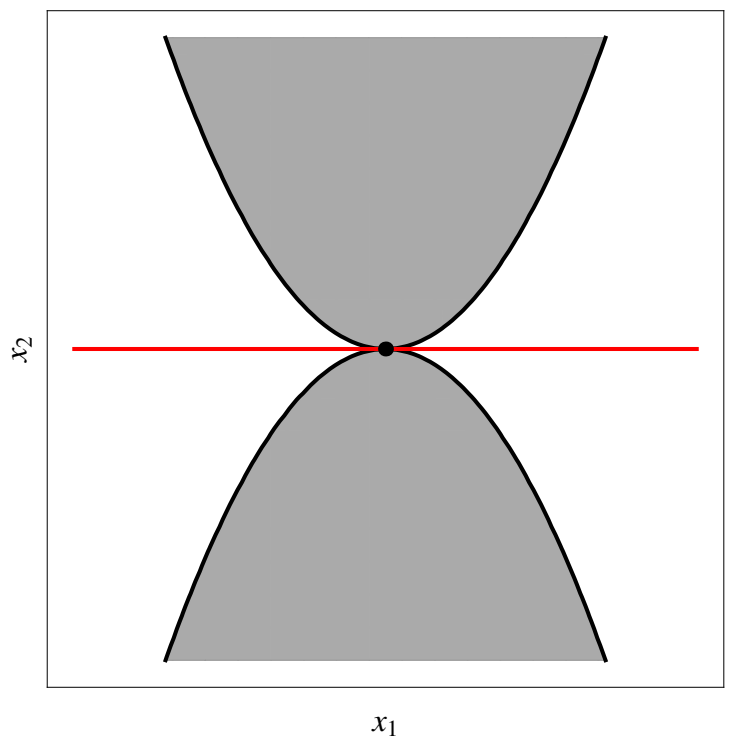

(a) $x_{2}+x_{1}^{2} \leq 0 \wedge x_{2}-x_{1}^{2} \geq 0$

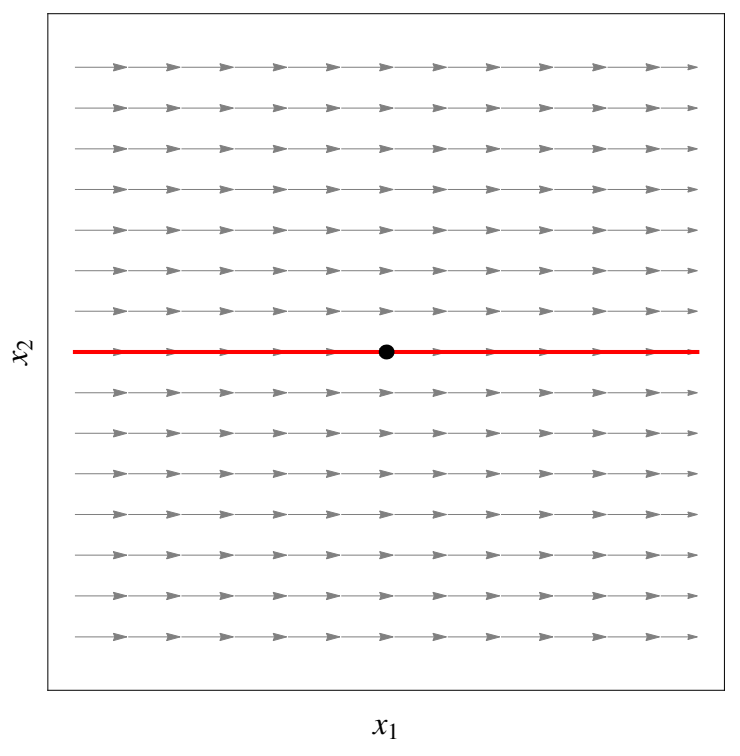

(b) $\dot{x}_{1}=1, \dot{x}_{2}=0$

Figure 7: Example of unsoundness in [30]. Intersection of contingent cones to the conjuncts at 0 is shown in red. 